\title{
ORGANIZED ILLUSIONS: A BEHAVIORAL THEORY OF WHY CORPORATIONS MISLEAD STOCK MARKET INVESTORS (AND CAUSE OTHER SOCIAL HARMS)
}

\author{
DONALD C. LANGEVOORT ${ }^{\dagger}$
}

Rationality is a strong assumption in the legal literature about how corporations and other organizations behave in market settings. The modern transaction-cost economics on which most contemporary corporate scholarship is based ${ }^{1}$ concedes that the rationality of officers, directors, and other managers is "bounded" (that is, that they do not have perfect information or unlimited time, skill, and attention) and acknowledges that these agents have self-interests that differ from those of their firms' owners. ${ }^{2}$ Because of these limits and the imper-

† Lee S. \& Charles A. Speir Professor, Vanderbilt University School of Law. The author would like to thank Jim Cox, Eric Orts, and the many participants at workshops and presentations at Stanford University, the University of Michigan, and the University of Illinois for their very helpful comments.

${ }^{1}$ This literature is sufficiently pervasive that it hardly needs extensive citation; key legal texts in corporate law include FRANK H. EASTERBROOK \& DANIEL R. FISCHEL, THE ECONOMIC STRUCTURE OF CORPORATE LAW (1991); PRINCIPALS AND AGENTS (John W. Pratt \& Richard J. Zeckhauser eds., 1985); ROBERTA ROMANO, THE GENIUS OF AMERICAN CORPORATE LAW (1993); and Symposium, Contractual Freedom in Corporate Law, 89 COLUM. L. REV. 1395 (1989). This is not to say that it is uncontroversial; legal critics have questioned its power and accuracy from any number of perspectives. See, e.g., Douglas M. Branson, The Death of Contractualism and the Vindication of Structure and Authority in Comporate Law Governance and Corporate Law, in PROGRESSIVE CORPORATE LAw 93, 93, 105 (Lawrence Mitchell ed., 1995) (arguing that law-and-economics theories do not adequately justify a hands-off approach to corporate law, so that " $[t]$ here must be structure and a core of principles and authority in corporate law"). But most critiques focus primarily on the ineffectiveness of contract as a mechanism for reconciling the competing interests, see, e.g., id. at 94 (arguing that " $[u] n d e r$ a contractarian scheme, all but larger minority interests ... would be discouraged"), leading to the view that absent legally imposed restraints, managers really are entrenched and free to act selfishly and antisocially, $c f . i d$. at 97 (noting that "there exist some immutable rules and principles that govern behavior and check unbridled majority power in the corporate sphere").

${ }^{2}$ See, e.g., Oliver E. Williamson, Economic InstTrutions of CAPITALISM 43-52 (1985) (discussing bounded rationality and "the behavioral assumptions imputed to contractual man"); Michael C. Jensen \& William H. Meckling, Theory of the Firm: Managerial Behavior, Agency Costs and Ownership Structure, 3 J. FIN. ECON. 305, 309 (1976) (identifying and analyzing agency costs which affect the relationship between firm owners and management). For a review of the agency-cost branch, see Kathleen M. Eisenhardt, Agency Theory: An Assessment and Review, 14 ACAD. MGMT. REV. 57 (1989). 
fection of contractual and other mechanisms for resolving them, firms will not always act in a way that maximizes shareholder wealth. But within such limitations, the world that is portrayed is still one of guileful rationality. Firms that depart too far or too often from this norm will lose access to needed capital and succumb to their more savvy competitors. Managers are presumed to understand this and act accordingly.

Borrowing from an explosion of work by social scientists on human judgment and decisionmaking, legal scholars have been increasingly willing to rethink strong assumptions of rationality in the context of individual behavior, even within markets. ${ }^{3}$ They have not yet mined to any depth, however, an equally rich vein of research on organizational rationality. ${ }^{4}$ Yet here we find the skeptic's mother lode:

${ }^{3}$ In the past decade, there has been a burgeoning literature in both law and economics on human decisionmaking and the possibility for heuristics and biases to operate instead of conventional Bayesian rationality. For reviews of some of this research within the social sciences, see Colin Camerer, Individual Decision Making, in THE HANDBOOK OF EXPERIMENTAL ECONOMICS 587 (John H. Kagel \& Alvin E. Roth eds., 1995); Conference, The Behavioral Foundations of Economic Theory, 59 J. Bus. S181 (1986); John Conlisk, Why Bounded Rationality?, 34 J. ECON. LITERATURE 669 (1996); Lola L. Lopes, Psychology and Economics: Perspectives on Risk, Cooperation, and the Marketplace, 45 ANN. REV. PSYCHOL. 197 (1994). For a small sampling of the contemporary legal work invoking this material, see Melvin Aron Eisenberg, The Limits of Cognition and the Limits of Contract, 47 STAN. L. REV. 211 (1995); Robert C. Ellickson, Bringing Culture and Human Frailty to Rational Actors: A Critique of Classical Law and Economics, 65 CHI.-KENT L. REV. 23 (1989); Russell Korobkin \& Chris Guthrie, Psychological Barriers to Litigation Settlement: An Experimental Approach, 93 MiCH. L. REV. 107 (1994); Donald C. Langevoort, Selling Hope, Selling Risk: Some Lessons for Law from Behavioral Economics About Stockbrokers and Sophisticated Customers, 84 CAL. L. REV. 627 (1996); and Roger G. Noll \& James E. Krier, Some Implications of Cognitive Psychology for Risk Regulation, $19 \mathrm{~J}$. LEGAL STUD. 747 (1990). For a review, see Thomas S. Ulen, Rational Choice and the Economic Analysis of Law, 19 L. \& SOC. INQUIRY 487 (1994). In contrasting these "biases" with rationality, I do not mean to imply that they may not be adaptive; that is an intriguing problem that will be explored later in this Article. See also Robert E. Scott, Error and Rationality in Individual Decisionmaking: An Essay on the Relationship Between Cognitive Illusions and the Management of Choices, 59 S. CAL. L. REv. 329, 332 (1986) ("A theory of choice management, which recognizes that individuals deliberately regulate their choices and adopt strategies to accomplish their goals, yields richer explanations of the function of many legal rules."). Notwithstanding the problems associated with its definition, I will use rationality in its standard economic sense.

In criminal law, organization theory has had a considerable impact due largely to the long-standing interest of sociologists in white-collar crime. See, e.g., CHRISTOPHER D. STONE, WHERE THE LAW ENDS 35-36 (1972) (discussing society's inability to monitor and control illegal corporate behavior); John C. Coffee, Jr., Beyond the Shut-Eyed Sentry: Toward a Theoretical View of Corporate Misconduct and an Effective Legal Response, 63 VA. L. REV. 1099, 1101 (1977) (proposing a shift from "moralistic' legal responses, which seek to maximize the public reprobation and symbolic denunciation of the conduct in question, [to] 'pragmatic' legal responses, which focus instead on prevention and 
empirical accounts-grounded in sociology and social psychology, but increasingly integrated with economic analysis-for why organizations so often behave in the myopic, rigid manner that we seem to observe in the real world. This literature seeks to identify the social cognitions and norm structures ${ }^{5}$ within organizations that can lead to a "loose coupling" between day-to-day activities and instrumental rationality for reasons that go well beyond managerial opportunism. ${ }^{6}$ It works from the assumption that these social forces are sufficiently natural and ingrained that they cannot readily be eliminated by structural or contractual design, and sufficiently contingent on the personnel in place at any given time and the situation in which the firm

therefore seek to optimize whatever conditions within the system most inhibit the disapproved conduct"); Diane Vaughn, Toward Understanding Unlawful Organizational Behavior, 80 MICH. L. REV. 1377, 1378 (1982) (examining the impact of American societal norms and internal corporate structures on unlawful corporate behavior). Even here, however, there has been more emphasis on the orthodox sociological conception of the firm as opposed to the new institutionalism's focus on cognitions and belief structures.

5 Both individual ("micro") and broad social behaviors ("macro") are the subject of inquiry within this literature; the micro-macro distinction, though fuzzy, is a common one. The macro-behavioral accounts (which traditionally have been dominant) are largely sociological in nature, emphasizing the cultural forces that dominate the cognitions and behaviors of individual actors. See Alison Davis-Blake \& Jeffrey Pfeffer, Just a Mirage: The Search for Dispositional Effects in Organizational Research, 14 ACAD. MGMT. REV. 385, 397 (1989) (criticizing an organizational-behavior research approach that "tends to allow organizational participants to escape responsibility for the systems they design"). The micro-behavioral emphasis, which draws heavily from the socialcognition branch of psychology that is having such an impact in law and economics, looks at individual cognitive traits to see how these can affect the behavior of the larger organization. See supra note 3. For an effort at integration, see Barry M. Staw \& Robert I. Sutton, Macro Organizational Psychology, in SOCIAL PSYCHOLOGY IN ORGANIZATIONS 350 (J. Keith Murnighan ed., 1993).

${ }^{6}$ Good overviews can be found in W. RICHARD SCOTT, ORGANIZATIONS: RATIONAL, NATURAL, AND OPEN SYSTEMS (3d ed. 1992), and THE NEW INSTITUTIONALISM IN ORganizational ANalysis (Walter W. Powell \& Paul J. DiMaggio eds., 1991) [hereinafter THE NEW INSTITUTIONALISM]. For efforts to interest legal academics in these materials, see Walter W. Powell, Fields of Practice: Connections Between Law and Organizations, 21 L. \& SOC. INQUIRY 959 (1996), and Mark C. Suchman \& Lauren B. Edelman, Legal Rational Myths: The New Institutionalism and the Law and Society Tradition, 21 L. \& SOC. INQUIRY 903 (1996) (reviewing THE NEW INSTITUTIONALISM, supra). For an earlier survey, see Michael B. Metzger, Organizations and the Law, 25 AM. BUS. L.J. 407 (1987). I have used this research to connect questions of corporate law and the professional responsibility of corporate lawyers in Donald C. Langevoort, The Epistemology of Conporate-Securities Lawyering: Beliefs, Biases and Organizational Behavior, 63 BROOK. L. REV. (forthcoming 1998). Outside of corporate law, a constitutional-law text that makes considerable use of modern organization theory is MEIR DAN-COHEN, RIGHTS, PERSONS, AND ORGANIZATIONS (1986); for a critique, with particular reference to the social-psychological genre, see Richard B. Stewart, Organizational Jurisprudence, 101 HARV. L. REV. 371, 378-80 (1987) (reviewing DAN-COHEN, supra). 
finds itself that they cannot easily be learned away. Competitive forces are not irrelevant, but are only part of a complex set of institutional influences that operates over the entire marketplace. ${ }^{7}$

This research affects a good bit of what is taught as organizational behavior in business schools. There, managerial rationality tends to be treated more as a holy grail than as an observable reality: Empirical case studies abound of systemic decisionmaking flaws, with many of the examples drawn from companies hardly destined for Darwinian extinction. Take, for instance, Robert Burgelman's study of Intel Corporation's loss of a strong competitive advantage over a twentyyear period (roughly 1971-1991) in the dynamic random access memory (DRAM) market. ${ }^{8}$ Ultimately, Intel recognized the error and successfully repositioned itself in the microprocessor business. ${ }^{9}$ In the end, then, Intel did adapt; no doubt market discipline drove the hard lesson. But the interesting questions are why it took so long, and whether it could happen to Intel again in some different context. To offer answers to these questions here would be to give away too much of what is to follow in this Article. Suffice it to say that many organizational theorists suggest that the cognitive and informational difficulties that overcame Intel are pervasive and commonplace. Much of their theory is social constructionist, going to how organizations perceive themselves, their goals, and their environment, and the potential for myths in conditions of high ambiguity. ${ }^{10}$

${ }^{7}$ See Paul J. DiMaggio \& Walter W. Powell, Introduction to THE NEW INSTITUTIONALISM, supra note 6 , at 1,32 ("Rather than deny the importance of competition, institutional theorists now emphasize the historical and intersocietal variability of competitive regimes and the role of institutions in constituting those regimes.").

${ }^{8}$ See Robert A. Burgelman, Fading Memories: A Process Theory of Strategic Business Exit in Dynamic Environments, 39 ADMIN. SCI. Q. 24, 26 (1994) (chronicling and analyzing the strategic business decision to exit the DRAM market and focus resources on the microprocessor market). For a critique, see CHRIS ARGYRIS \& DONALD SCHÖN, ORGANIZATIONAL LEARNING II, at 211-21 (1996).

${ }^{9}$ See Burgelman, supra note 8 , at 41 .

${ }^{10}$ See, e.g., KARL E. WEICK, SENSEMAKING IN ORganizations 63-82 (1995) (discussing how a corporation shapes organizational structure and behavior via the sensemaking process); James G. March \& Johan P. Olsen, The Uncertainty of the Past: Organizational Learning Under Ambiguity, in JAMES G. MARCH, DECISIONS AND ORGANIZATIONS 350-56 (1988) (discussing how organizational participants learn and interpret events); John W. Meyer \& Brian Rowan, Institutionalized Organizations: Formal Structure as Myth and Ceremony, 83 AM. J. Soc. 340, 341 (1977) (arguing "that the formal structures of many organizations in postindustrial society dramatically reflect the myths of their institutional environments instead of the demands of their work activities"); Suchman \& Edelman, supra note 6, at 910-13 (discussing cognitive institutionalism and behavioral institutionalism). 
My immediate interest in this scholarship stems from a continuing fascination with a fundamental question in securities regulation and the primary focus of this Article: Why do companies falsely portray themselves to the capital markets in filings with the Securities and Exchange Commission (the "SEC") and through other publicity? The most common sort of large-scale class-action lawsuit alleging securities fraud is one brought against a public corporation and its senior management for concealing bad news from investors, even though the company was not in the process of selling its own shares at the time. This nonprivity "fraud-on-the-market"11 case typically involves some form of product or financial degeneration kept from public view until the last possible moment, leading to a rapid decline in the market price of the stock once the adverse information is disclosed, and a set of unhappy investors who bought at a time, they suspect, when the issuer's managers knew of the problems but nonetheless kept an optimistic public face. ${ }^{12}$ Scores of cases decided by the courts each year under the principal antifraud provision of the SEC's regulations, Rule $10 \mathrm{~b}-5,{ }^{13}$ fall into this category. In 1995 , Congress passed the Private Securities Litigation Reform Act ${ }^{14}$ largely to deal with perceived abuses associated with this kind of lawsuit. ${ }^{15}$

" Under the fraud-on-the-market theory, investors who buy or sell in an efficient market after some material misrepresentation or omission are presumed to have relied upon it, a presumption that is all but unrebuttable in fact. See, e.g., JAMES D. COX ET AL., SECURITIES REGULATION 753 (2d ed. 1997) ("Because most publicly available information is reflected in market price, an investor's reliance on any public material misrepresentations, therefore, may be presumed for purposes of a Rule 10b-5 action."). The result is that the class of investors who can recover, and thus the aggregate amount of recovery, is potentially very large.

${ }_{12}$ A standard example is In re Apple Computer Securities Litigation, 886 F.2d 1109 (9th Cir. 1989). See infra note 157 and accompanying text; see also Robert A. Prentice \& John H. Langmore, Beware of Vaporware: Product Hype and the Securities Fraud Liability of High-Tech Companies, 8 HARV. J.L. \& TECH. 1, 4 (1994) (discussing product hype in relation to Rule $10 \mathrm{~b}-5$ and $A p p l e$ ). For efforts to relate this problem to the behavioraleconomics literature in terms of investor (that is, victim) decisionmaking within market constraints, see Donald C. Langevoort, Theories, Assumptions, and Securities Regulation: Market Efficiency Revisited, 140 U. PA. L. REV. 851 (1992). A noteworthy use of the economic model that grows at least in part from the behaviorist perspective, noise theory, is Baruch Lev \& Meiring de Villiers, Stock Price Crashes and 10b-5 Damages: A Legal, Economic, and Policy Analysis, 47 STAN. L. REV. 7 (1994).

13 C.F.R. $\$ 240.10 \mathrm{~b}-5$ (1997).

14 Pub. L. No. 104-67, 109 Stat. 737 (1995).

${ }^{15}$ See, e.g., Richard M. Phillips \& Gilbert C. Miller, The Private Securities Litigation Reform Act of 1995: Rebalancing Litigation Risks and Rewards for Class Action Plaintiffs, Defendants and Lawyers, 51 Bus. LAw. 1009, 1010-11, 1018 (1996) (stating that Congress passed the Private Securities Litigation Reform Act in order to "reduc[e] the inci- 
My intuition is that stories like Intel, if accurate, have something to say about this question. If Intel's business judgment was skewed by predictable social forces, its economic self-portrait in disclosure about its business prospects perhaps was as well. ${ }^{16}$ This insight helps us solve a puzzle. From a rational standpoint, why would public companies ever deliberately lie to investors when, because they are neither buying nor selling stock in the open market, there is nothing directly to gain? When done intentionally, such activity is clearly unlawful and policed fairly visibly both by the SEC and the private plaintiffs' classaction bar. Yet cases of alleged deception seem to persist in large numbers. Of course, anything but the most strained anthropomorphic conception of the firm leads us quickly to observe that corporations cannot tell lies-only their managers can. The question of motivation, then, becomes largely a managerial one. But conventional economic analysis, at least, tells us that the interests of the company's highest executives are usually (albeit not always) fairly closely aligned with the ongoing interests of the firm, so that the question of why senior managers would engage in secondary-market deception remains an interesting one. This is especially so when one considers that in most bad-news scenarios, concealment simply delays the appreciation of the truth rather than avoids it indefinitely, ${ }^{17}$ so that there are adverse reputational as well as legal consequences from concealing the truth.

The question has practical importance. From the standpoint of securities-litigation policy, a conclusion that managers seldom have a strong motive to lie under the prevailing regulatory framework (or have such motive only in special, confined circumstances) might lead us to doubt the merits of many of the fraud-on-the-market lawsuits brought today. This would lend inferential support to the view that the bulk of these cases are brought extortionately for their settlement value, ${ }^{18}$ and justify the kind of aggressive pruning of such actions that

dence of speculative class action suits, while still preserving meaningful class action remedies for meritorious securities fraud claims").

${ }^{16}$ Because this analysis could not be done thoroughly and fairly from readily available sources, I have made no effort to determine whether Intel's publicity was actually distorted.

${ }^{17}$ See In re Time Warner Inc. Sec. Litig., 9 F.3d 259, 272-75 (2d Cir. 1993) (Winter, J., dissenting) (arguing that the timing of bad news is irrelevant due to the efficientmarket hypothesis).

${ }^{18}$ Cf. Joseph A. Grundfest, Disimplying Private Rights of Action Under the Federal Securities Laws: The Commission's Authority, 107 HARV. L. REv. 963, 1017-24 (1994) (arguing that the SEC should institute a rulemaking proceeding to explore, if, when, and how 
Congress chose in 1995. Conversely, identifying a broader set of plausible motivations would suggest that there might well be plenty of securities fraud around, suggesting the need for care in the reform efforts lest too much deterrence be lost.

This Article seeks to provide a robust set of explanations for why managers of a public corporation would mislead stock market investors either in their filings or in ongoing publicity efforts. Part I begins by tracing the intellectual history of prior answers to this question. As we shall see, there are very good-but confinedexplanations within the framework of conventional economic analysis, particularly the thesis advocated by Jennifer Arlen and William Carney ${ }^{19}$ that in the face of the sort of liability now imposed for securities fraud (which is almost exclusively vicarious), open-market lies are predictable if (but largely only if) the top managers see themselves as facing a "last period problem" wherein the disclosure of the truth would result in insolvency and hence the loss of their jobs. The primary use of institutionalist organization theory here is simply to emphasize that the cost-benefit calculation that managers face when deciding whether to lie is a complex one: Firms have multiple constituencies, and lies that influence investors may really be directed at other audiences (for example, customers or employees) in order to prevent "runs" on external or internal resources.

We then turn to alternative stories that draw from materials that, as noted above, blend the insights of sociology and social psychology with economic analysis. Part II will move only slightly, if at all, from the world of economics in utilizing this literature. Part II extends the agency-cost analysis by raising the possibility that some forms of misleading may be traceable not to the distortion of information by the senior managers themselves but by arguably selfish distortions by lower-level managers in the flow of information that moves up to senior management. The interesting question here is whether the resulting misinformation to the marketplace is securities fraud at all.

Part III is the heart of this Article and will make much greater use of institutional theory as it has evolved in work on organizations outside of mainstream economics. Organizations are not the product of

private rights should be administratively disimplied). This is not the only inference, of course: Deficiencies in the prevailing regulatory structure could also play a role.

${ }^{19}$ See Jennifer H. Arlen \& William J. Carney, Vicarious Liability for Fraud on Securities Markets: Theory and Evidence, 1992 U. ILL. L. REV. 691, 72427 (summarizing data which show that fraud on the market generally occurs when agents are afraid that they are in their last period of employment). 
preexisting or stable preferences of a group of individual actors; instead, the structures and norms that have already evolved determine what those actors prefer and how they make sense of what is happening around them. Here, we see the possibility that managers simply might not recognize problems or risks because of systematic "perceptual filters" ${ }^{20}$ that play crucial protective roles in the smooth functioning of the firm. My most provocative hypothesis is that corporate cultural biases, particularly optimistic ones, can be adaptive mechanisms for encouraging trust and cooperation, and for deflecting the selfishness-inducing last-period problem that arises in times of stress and threat. If so, then such cultures should be commonplace and persistent. This possibility is interesting especially when combined with the problems specified in Parts I and II. The last-period and information-flow questions become even more complex and fascinating if we predict that cognitive biases affect the perceptions of those involved in both the information flow and disclosure processes.

Though this Article is specifically directed at the problem of securities fraud, my broader aim is to invoke the new institutionalist literature in a way that makes clear its usefulness in a wide range of legal settings, ${ }^{21}$ and thereby prompt a research agenda to build on this genre of organization theory. The transaction-cost economics of Oliver Williamson, Michael Jensen, and others has justifiably had a profound influence on many legal subjects, not just corporate law. One can hardly criticize this investment of intellectual capital, except to the extent that it purports to be preemptive. Williamson and

${ }^{20}$ See William H. Starbuck \& Frances J. Milliken, Executives' Perceptual Filters: What They Notice and How They Make Sense, in THE ExECUTIVE EFFECT 35, 38 (Donald C. Hambrick ed., 1988) (noting that explanations for organizational failure often center on executives' failure to assess risk); see also Janice M. Beyer et al., The Selective Perception of Managers Revisited, 40 ACAD. MGMT. J. 716, 734 (1997) (discussing different studies of selective perception and concluding that managers' information processing is influenced by their functional experience); Dennis A. Gioia, Symbols, Scripts and Sensemaking: Creating Meaning in the Organizational Experience, in THE THINKING ORGANIZATION 49, 54-55 (Henry P. Sims, Jr. \& Dennis A. Gioia eds., 1986) (stating that sense is made of any current experience by imposing an existing framework on the current observation); sources cited infra note 110. For an extremely thorough review of the organizational-cognition literature (only a small portion of which deals with bias as opposed to bounded rationality), with many references to business case studies, see James $P$. Walsh, Managerial and Organizational Cognition: Notes from a Trip Down Memory Lane, 6 ORG. SCI. 280 (1995).

${ }^{21}$ For one example of a call for this kind of connective work, see Edward L. Rubin, The New Legal Process, the Synthesis of Discourse, and the Microanalysis of Institutions, 109 HARV. L. REV. 1393, 1416 (1996) (noting the convergence of economics, psychology, sociology, and anthropology in institutional scholarship). 
Jensen, like many other economists, have explicitly acknowledged that economists have something to learn from the sociologists and social psychologists who work in organizational theory (and vice versa, of course), namely that an integrated institutional theory is desirable but still in developmental infancy. ${ }^{22}$ But this acknowledgment has not yet led legal scholars to anything resembling a comparable investment of efforts in exploring those other disciplines for useful insights: ${ }^{23}$ To this end, Part IV will seek to generalize some of the ideas about the motivations underlying corporate deception and extend them to the more fundamental question of the responsiveness of corporations to the dictates of tort and criminal law. Why might corporations not act "rationally" in avoiding socially harmful, unlawful activities such as the production of dangerous products or the discharge of toxic waste?

\section{WHY LIE? THE PREVAILING ACCOUNTS}

Securities "lies" come in a variety of forms. One can misrepresent hard data (for example, lie about accounting results or a large con-

${ }_{22}$ See George P. Baker et al., Compensation and Incentives: Practice vs. Theory, $43 \mathrm{~J}$. FIN. 593, 615 (1988) ("Ultimately, it may be that psychologists, behaviorists, human resource consultants, and personnel executives understand something about human behavior and motivation that is not yet captured in our economic models."); Oliver E. Williamson, Introduction to ORGANIZATION THEORY: FROM CHESTER BARNARD TO THE PRESENT AND BEYOND 3, 9 (Oliver E. Williamson ed., 1990) ("A fruitful dialogue between economics and organization is progressively taking shape."). The tribute to the work of Chester Barnard organized by Williamson, see id., is an excellent dialogue between economists and a diverse group of other social scientists about the opportunities to advance organization theory via multidisciplinary work. In fact, economists have been much quicker to incorporate these multidisciplinary perspectives into their work than economics-oriented legal scholars. See Langevoort, supra note 12, at 857-72 (surveying use of social and psychological research in finance theory). Modern institutional economics is notable for its emphasis on historical and social theories (for example, evolutionary and path-dependent development) even when it does not make specific use of psychology or sociology. For law-oriented surveys, see Ronald J. Gilson, Comporate Governance and Economic Efficiency: When Do Institutions Matter?, 74 WASH. U. L.Q. 327 (1996), and Rubin, supra note 21.

${ }^{23}$ A predictable but crucial disclaimer is necessary here. There is no singular model of organizational behavior in the new institutional literature: The underlying theories and assumptions are controversial and often highly contingent. The field is still relatively young. My aim here is to invoke that literature as the basis for promising insights for legal scholars and decisionmakers, without claiming that it can be demonstrated empirically to be more valid than the economists' competing model of instrumental rationality. Citations are offered not to claim that an assertion is clearly correct but rather to demonstrate respectable academic support for this institutional literature's plausibility. 
tract that supposedly was agreed to with an important customer). Most information in SEC filings is of this sort. But many lies that seemingly have the capacity to affect the stock markets ${ }^{24}$ are much "softer"-involving subjective matters of opinion or inference. ${ }^{25} \mathrm{~A}$ company will be charged with withholding adverse information about whether a new product is likely to succeed, or whether cash flow is sufficient to buffer the firm through hard times. The underlying hard facts are interesting, that is, material, only for their predictive usefulness. In this sense, an important portion of the question of why companies allegedly lie to the stock markets can be recharacterized: Why do companies allegedly distort construals of their future prospects? $?^{26}$ That is our focus here.

The earliest literature on securities law rarely contained much discussion of the motivational question. The increasing incidence of cases involving misinformation disseminated to the secondary markets apparently led to an assumption that open-market fraud was a problem, without much specification beyond anecdotes as to why or how-even though, in the aftermath of the seminal Texas Gulf Sulphur

${ }^{24}$ I accept that many forms of managerial "spin" will be discounted by professional investors. See infra text accompanying notes 196-97.

${ }^{25}$ See COX ET AL., supra note 11, at 63-89 (discussing cases and materials dealing with speculative information and materiality, and forward-looking information); Victor Brudney, A Note on Materiality and Soft Information Under the Federal Securities Laws, 75 VA. L. REV. 723, 730-32 (1989) (discussing the concept of the materiality of soft or future-oriented information in the law of required disclosure). The Supreme Court has acknowledged that opinion-based disclosure can nonetheless be material, that is, the sort of assertion on which a reasonable investor might reasonably rely. See Virginia Bankshares v. Sandberg, 501 U.S. 1083, 1090-91 (1991) ("We think there is no room to deny that a statement of belief by corporate directors about a recommended course of action, or an explanation of their reasons for recommending it, can take on just that importance [of materiality].").

${ }^{26}$ This portion is quite large when one considers that fundamental valuation techniques concentrate solely on the firm's expected stream of earnings, which is then discounted to present value. Present and historic facts are simply useful in helping estimate the future. See, e.g., William A. KLEIN \& JOHN C. COFFEE, JR., BusinesS ORGANIZATION AND FINANCE 304-15 (6th ed. 1996) (discussing and illustrating various valuation techniques). 
litigation, ${ }^{27}$ this kind of fraud allegation in many ways became the poster child for increasingly aggressive federal securities regulation. ${ }^{28}$

By the mid-1970s, economic analysis of corporate and securities regulation had taken hold, quickly turning what had been a relatively moribund body of scholarship into one visibly prized in the academy. ${ }^{29}$ Given the strong emphasis on the comparative advantage of nonlegal, market-based constraints in controlling harmful forms of behavior, ${ }^{30}$ scholars naturally asked hard questions about the likely incidence of fraud and nondisclosure.

Two rational-actor insights are central to understanding the issue. One is that active securities fraud, unlike other forms of wrongdoing (like embezzlement, price fixing, and toxic dumping) is necessarily public rather than private. Directly or indirectly, the insider must speak through some medium, such as the business press or investment analysts, which can disseminate the fraud widely. Moreover, active securities fraud is largely within the control of a small group of senior managers, usually the only ones within the firm with enough credibility and access to information to be able to move market participants to cause significant price changes. In other words, a single manager is unlikely to have the opportunity to move the market, even if she wants to do so, without alerting other senior managers, who have the capacity to counter or deny the falsehood quickly. As such, one would expect that most successful frauds are committed with the

${ }^{27}$ See SEC v. Texas Gulf Sulphur Co., 401 F.2d 833, 864 (2d Cir. 1968) (in banc) ("We conclude... that, having established that the release was issued in a manner reasonably calculated to affect the market price of TGS stock and to influence the investing public, we must remand to the district court to decide whether the release was misleading to the reasonable investor and if found to be misleading, whether the court in its discretion should issue the injunction the SEC seeks.").

${ }^{28}$ See David S. Ruder, Texas Gulf Sulphur-The Second Round: Privity and State of Mind in Rule 10b.5 Purchase and Sale Cases, 63 Nw. U. L. REV. 423, 423 (1968) ("Serious questions regarding the extent to which liability should be imposed for violation of Securities and Exchange Commission Rule 10b-5 have been raised by the recent Second Circuit decision in SEC v. Texas Gulf Sulphur Co."). Notwithstanding greater conservatism in securities-law policy, the abandonment of privity has survived recent challenge. See McGann v. Ernst \& Young, 102 F.3d 390, 397 (9th Cir. 1996) (applying Texas Gulf Sulphur to an allegedly fraudulent audit report and concluding that "an accounting firm acts 'in connection with' securities trading when it produces an audit report").

${ }^{29}$ See Roberta Romano, Metapolitics and Corporate Law Reform, 36 STAN. L. REV. 923, 923 (1984) ("Until recently, corporate law has been an uninspiring field for research even to some of its most astute students.").

${ }^{\text {so }}$ See sources cited supra note 1. 
involvement or acquiescence of the entire management group of the corporation.

The other insight is that, collectively at least, this control group has a natural incentive toward candor. ${ }^{31}$ Senior management's group interests are contractually aligned with the long-term success of the firm as reflected in its share price, and the firm benefits from a reputation for honesty. Since few problems can be concealed indefinitely, especially in an environment of mandatory disclosure, with the intervention of outside accountants and lawyers as well as aggressive scrutiny by professional analysts, the reputational risk of concealment, both to the firm and its top executives, is palpable.

To be sure, special circumstances exist that could tempt this group to choose the risk. The most obvious is the possibility of insider trading-well recognized today as the best motivational story a plaintiff can tell to justify a circumstantial case for fraud on the market. $^{32}$ There is an immediate and potentially immense pecuniary gain for managers if they can buy or sell in advance of a market movement, tempting them to delay their truth-telling in order to fully exploit the informational advantage. But we must be cautious about the plausibility of this kind of story. Given that some concerted effort by senior managers is usually required to distort the market successfully, there are difficult coordination problems that act as natural deterrents to this kind of conspiracy. ${ }^{33}$ This kind of insider trading is unambiguously illegal and readily detectable when done on the kind of large scale necessary to support a broad conspiracy. ${ }^{34}$

${ }^{31}$ See Frank H. Easterbrook \& Daniel R. Fischel, Mandatory Disclosure and the Protection of Investors, 70 VA. L. REV. 669, 673-77 (1984) (describing management's interest in its own trustworthiness).

${ }^{32}$ See, e.g., Rubinstein v. Collins, 20 F.3d 160, $169-70$ (5th Cir. 1994) (noting the presumptive materiality of insider information). See generally Jordan Eth \& Michael Dicke, Insider Stock Sales in Rule 10b-5 Corporate Disclosure Cases: Separating the Innocent from the Suspicious, 1 STAN. J.L. BUS. \& FIN. 97, 98 (1994) (discussing corporate disclosure cases). Similarly, there would be an obvious pecuniary motivation to executives who are about to receive or cash in on stock options or comparable forms of compensation, or who wish to avoid the threat of a corporate takeover. A recent study finds little evidence of management's potentially manipulative timing of publicity as a means of maximizing compensation awards. See David Yermack, Good Timing: CEO Stock Option Awards and Company News Announcements, 52 J. FiN. 449, 473 (1997) (arguing against the theory that managers manipulate the timing of their news announcements).

${ }^{33}$ Given the risk of detection, many executives who would otherwise be privy to the fraud would lack the sufficient self-interest to participate.

${ }^{34}$ See, e.g., DONALD C. LANGEVOORT, INSIDER TRADING $\$ 1.04$, at I-23 (1997) (discussing how suspicious market-price movements can trigger SEC investigations). 
A more benign kind of temptation to lie or conceal information comes when there is some special corporate need to preserve secrecy. ${ }^{35}$ The best-known example here is the preliminary merger negotiation, addressed in the Supreme Court's Basic Inc. v. Levinson decision. ${ }^{36}$ On the not unrealistic assumption that preliminary negotiations are more likely to occur and succeed if they proceed without the knowledge of potential competitors for corporate control, companies have a natural incentive to keep investors in the dark (and foreseeably hurt some relatively small category of sellers) in pursuit of the overriding aim of maximizing firm value. One can easily imagine other analogous examples of this sort of deception. Scholars have debated the proper posture toward this situation; however, the Court in Basic made clear that utilitarian lying to cover up the negotiations may be illegal, ${ }^{37}$ even though mere silence probably is not. ${ }^{38}$ Once we assume illegality, ${ }^{39}$ we must again puzzle over why managers would rationally choose to run both the reputational and legal risk associated with lying when (the

35 See Marcel Kahan, Games, Lies, and Securities Fraud, 67 N.Y.U. L. REV. 750, 753 (1992) (describing a hypothetical company's incentive to keep its strategies secret).

${ }^{36} 485$ U.S. 224, 226 (1988) (discussing the Securities Exchange Act as it applies to preliminary merger discussions). There are many other cases in which deceiving some other audience was the primary objective of the misstatement or omission. See, e.g., Heit v. Weitzen, 402 F.2d 909, 911 (2d Cir. 1968) (failing to disclose overcharges on government contracts). Basic generated an interesting debate about whether corporations should have greater freedom to lie under the securities laws. See Ian Ayres, Back to Basics: Regulating How Corporations Speak to the Market, 77 VA. L. REV. 945, 946 (1991) (asking whether "corporations should be allowed to lie to the market"); Kahan, supra note 35, at 752 (noting that securities law may unfairly burden a company's strategic planning); Jonathan R. Macey \& Geoffrey P. Miller, Good Finance, Bad Economics: An Analysis of the Fraud-on-the-Market Theory, 42 STAN. L. REV. 1059, 1062 (1990) (discussing the gaps which the Basic decision leaves in the market-fraud theory).

${ }_{37} 485$ U.S. at 239 ("Whether merger discussions in any particular case are material depends on the facts.").

${ }^{3}$ See id. at 240 n.17 (" $[\mathrm{W}] \mathrm{e}$ think that creating an exception to a regulatory scheme founded on a prodisclosure legislative philosophy, because complying with the regulation might be 'bad for business,' is a role for Congress, not this Court.").

${ }^{39}$ Of course, the question of motivation depends on the nature of the liability scheme in question. If there is no liability at all for securities fraud, then the question is a simple calculus of whether the competitive benefits of secrecy exceed the reputational harm. If we assume firm liability, then the question is whether these benefits exceed the sum of the liability and reputational harm. In turn, the predicted liability costs would take into account the less-than-perfect incidence of a lawsuit and the fact that such suits can commonly be settled for far less than their face value. See, e.g., Janet Cooper Alexander, Do the Merits Matter?: A Study of Settlements in Securities Class Actions, 43 STAN. L. REV. 497, 524 (1991) ("[I]t seems clear that securities class actions are resolved by adjudication significantly less often than are other civil cases."). 
special problem of insider trading aside) they have so little to gain directly.

Here is where Arlen and Carney make their contribution. ${ }^{40}$ They hypothesize that so long as the interests of senior management are indeed aligned with the long-term interests of the firm, the incentive structure makes the probability of intentional deception somewhat unlikely. ${ }^{41}$ There will be one class of cases, however, where the motivational dynamics change considerably. If the senior management group believes that it faces the threat of company insolvency, with the high probability of group firing, then it will see the tradeoff for not lying as one of the threatened loss of salary, bonuses, and perquisites, plus any personal reputational damage resulting from such a termination. ${ }^{42}$ That is a draconian threat indeed, and even a rational actor will be tempted to avoid it through concealment, either to buy time to create the possibility of a turnaround or simply to milk their positions for as long as possible. ${ }^{43}$ Arlen and Carney note that the legal deterrence is minimal for selfish managers in light of the prevailing doctrinal regime's strong bias toward vicarious liability, ${ }^{44}$ wherein nearly all settlements and judgments are paid either by the company itself or its director and officer liability insurer-not by the managers themselves. ${ }^{45}$ Indeed, advocating a shift from vicarious to agent liability, a contrast with the orthodox preference in the law-and-economics literature, is the central normative message of their article.

We now have an account for some incidence of securities fraud, but the implication is that securities fraud is limited to special kinds of situations: particularly, when there is fear of being on the verge of

${ }^{10}$ See Arlen \& Carney, supra note 19. For an endorsement of their view, see Reinier Kraakman et al., When Are Shareholder Suits in Shareholder Interests?, 82 GEO. L.J. 1733,1760 n.80 (1994).

${ }^{11}$ See Arlen \& Carney, supra note 19, at 702-03 (describing market-based constraints).

${ }^{42}$ See id. at 693 (noting that "Fraud on the Market usually occurs when agents fear themselves to be in their last period of employment").

${ }^{43}$ See id. at 694 (arguing that generally fraud is committed by managers who want to conceal "that the firm is ailing in an attempt to save their jobs and their investments in the firm"). liability).

14 See id. (arguing that agent liability is a better deterrent of fraud than enterprise

${ }^{45}$ One recent study shows that only $0.4 \%$ of the average settlement is paid by the human wrongdoers; the remainder is from the corporate treasury or insurance (the premiums for which were paid by the company). See Frederick C. DUNBAR ET AL., RECENT TRENDS III: WHAT EXPLAINS SETTLEMENTS IN SHAREHOLDER CLASS ACTIONS? at $v$ (1995). 
bankruptcy or some other last period, or when there is a strong competitive need for secrecy. ${ }^{46}$ The problem with this theory, however, is that it does not provide a compelling motivational story for the majority of cases that make up the class-action practice today, and that involve the management's concealment of product defects or the company's financial difficulties that are unlikely to lead to insolvency.

One need not invoke much alternative organizational theory to appreciate the thesis of Arlen and Carney. One suspects, however, that in one respect a company may have a more pervasive incentive to lie than Arlen and Carney imply. One of the primary lessons of the institutionalist literature-hardly inconsistent with modern economic analysis-is that firms operate in complex ecologies in which they compete for both legitimacy and scarce resources. ${ }^{47}$ The relevant "stakeholder" network includes the government, employees, customers, suppliers, investors, and so forth. The management of the business requires constant care of all these relationships and occasional tradeoff of interests. Under these circumstances, it would not be surprising to find situations in which trading off credibility with (perhaps even the risk of liability to ${ }^{48}$ ) investors for some profit-enhancing gain in some other area could be a rational choice.

When a company issues a press release, there are many different groups of audience, and no public form of communication is capable of simultaneously delivering one message to investors while sending a completely different message to another group. The financial press (for example, the Wall Street Joumal or Business Week) is read by a wide variety of economic actors. The optimal form of publicity is one that best mediates the company's investor-relations interests with the full range of other business needs, adjusted to reflect whatever liability and reputational risks are associated with misleading any one class of actors. In the eyes of many students of business organizations, for example, there is a social imperative to style corporate publicity in a way

${ }^{16}$ Arlen and Carney provide an empirical study of recent class-action litigation (excluding merger and acquisition activities) that purports to support this thesis. See Arlen \& Carney, supra note 19, at 720-34. They categorize a sample of recent cases and argue that a large portion can be fit into the "last period" category. Seeid. at 725-27.

${ }^{17}$ See, e.g., Jefrrey Pfeffer \& Gerald R. SALANCIK, The External Control of ORGANIZATIONS 2 (1978) (arguing that because the success of an organization depends on its ability to acquire resources, it must contend with the environment in which its resources are controlled); SCOTT, supra note 6, at 76-94 (discussing the theory of open systems).

${ }^{43}$ This is especially the case if the expected harm from being caught is significantly less than the full social cost of the fraud. See supra note 39. 
that creates a strong image of confidence and control over the company's environment. ${ }^{49}$ Failure to do this results in a "run" on resources, a cascading loss of support that can endanger the particular project or, in extreme cases, the firm itself. ${ }^{50}$ We might go so far as to predict that companies that are not careful and unified in assuring that all its external publicity conforms to the desired image will risk signaling weakness. Under these circumstances, an excessively optimistic "face" of the corporation could readily become the norm, and any corporation that defected from the norm by being entirely candid would suffer a penalty if the stock market had so internalized an expectation of overoptimism that the truthful statement was taken as covering up a situation worse than depicted. This suggests some merit to the recent claim in a securities-fraud opinion by Judge Richard Posner that " $[w]$ here puffing is the order of the day, literal truth can be profoundly misleading."

${ }^{49}$ See, e.g., Jeffrey Pfeffer, Management as Symbolic Action: The Creation and Maintenance of Organizational Paradigms, in 3 RESEARCH IN ORGANIZATIONAL BEHAVIOR 1, 4 (L.L. Cummings \& Barry M. Staw eds., 1981) (stating that "it is the task of management to provide explanations, rationalizations, and legitimation for the activities undertaken in the organization"); Gerald R. Salancik \& James R. Meindl, Comporate Attributions as Strategic Illusions of Management Control, 29 ADMIN. SCI. Q. 238, 251-53 (1984) (examining reasons given by CEOs to explain corporate performance); Barry M. Staw et al., The Justification of Organizational Performance, 28 ADMIN. SCI. Q. 582, 59498 (1983) (discussing studies measuring justification of organizational performance). For a more critical perspective, see Charles R. Schwenk, Illusions of Management Control?: Effects of Self-Serving Attributions on Resource Commitments and Confidence in Management, 43 HUM. REL. 333, 334 (1990) (describing experiments to determine the "effects of self serving attributions on confidence in management and resource commitment decisions ${ }^{n}$ ).

${ }^{50}$ See Robert I. Sutton, Organizational Decline Processes: A Social Psychological Perspective, in 12 RESEARCH IN ORGANIZATIONAL BEHAVIOR, 205, 220-21 (Barry M. Staw \& L.L. Cummings eds., 1990) (stating that the "deterioration in an organization's environmental resource base causes a decrease in the flow of resources into the organization, especially financial resources, leading to decreased internal financial resources" and "emphasiz[ing] the role of a tainted organizational image in hampering the flow of resources from key external exchange partners"); Robert I. Sutton \& Anita L. Callahan, The Stigma of Bankruptcy: Spoiled Organizational Image and Its Management, 30 ACAD. MGMT. J. 405, 431 (1987) ("The stigma of Chapter 11 is proposed to cause key organizational audiences to respond with a set of five negative reactions: disengagement, reduction in the quality of participation, bargaining for more favorable exchange relationships, denigration via rumor, and denigration via confrontation."). For variations in the way in which firms react to financial threats, see William Ocasio, The Enactment of Economic Adversity: A Reconciliation of Failure Induced Change and Threat Rigidity, in 17 RESEARCH IN ORGANIZATIONAL BEHAVIOR 287 (L.L. Cummings \& Barry M. Staw eds., 1995).

${ }^{51}$ Eisenstadt v. Centel Corp., 113 F.3d 738, 746 (7th Cir. 1997). The idea that a norm of financial beautification through artificial accounting conventions can cause 
In moderate form, the multiple-audience problem could well be the story behind the "product fraud" cases that loom so large as securities class actions. Many cases-In re Apple Computer Securities Litiga$t_{i o n}{ }^{52}$ is a well-known example-have been based on a series of public statements regarding some product under development which has been greeted with great enthusiasm by the investing public but which then flops in the market. Some evidence is then found that problems were known to at least some managers at the time the optimism was being expressed. If we simply view this through the investor-company relationship lens, the fake optimism may seem puzzling, at least from a rational perspective.

But it is not so puzzling if we see the false publicity as directed to other audiences. Disclosure by the company of problems could well trigger competitors' gaining advantages with retailers and customers (for example, loss of anticipated shelf space). Unless the problems are already common knowledge among employees, there could be a slippage in internal motivation and morale. In other words, the disclosure could become a self-fulfilling prophecy, dooming whatever remaining chances of success the project has. More generally, disclosure of possibly insolvable problems and risks runs counter to the desired image of control treated by business theorists as so important in the competition for resources. Of course, there are possibly more selfish motivations at play here as well. Admission that an established project may be a failure is embarrassing to certain senior managers, threatening the prevailing political structure of the firm. However, we cannot assume that the desire to mislead is necessarily selfish. ${ }^{53}$

Nothing in the foregoing suggests that we should not attach liability consequences to these utilitarian sorts of lies. Although there has been a lively debate in the literature about how investors would view a

companies to conform for fear of being penalized if they do not is explored in Claire A. Hill, Why Financial Appearances Might Matter: An Explanation for "Dirty Pooling" and Some Other Types of Financial Cosmetics, 22 DEL. J. CORP. L. 141, 179-80 (1997).

${ }^{52} 886$ F.2d 1109 (9th Cir. 1989); see also Dale E. Barnes, Jr. \& Constance E. Bagley, Great Expectations: Risk Management Through Risk Disclosure, 1 STAN. J.L. BuS. \& FIN. 155, 170-71 (1994) (discussing consequences of public statements made in Apple); Prentice \& Langmore, supra note 12, at 1 (stating that after Apple, "the point is made: potentially huge securities liability can arise from statements made by corporate officials to promote their companies' products").

${ }^{53}$ I do not want to overstate my claim here, especially given the conclusions of Part III which suggest that managers are not likely to be fully conscious of the biased nature of their perceptions. 
rule that permitted a company to lie in order to enhance value, ${ }^{54}$ the courts have made clear that investors harmed by deliberate deception must be compensated, no matter how noble the reason. ${ }^{55}$ What is underscored, however, is the way in which the self-fulfilling prophecy consequence of candor can impose second-level costs on business firms, which are ultimately borne by investors. ${ }^{56}$ If public expressions of efficacy and control are frustrated, corporations may suffer competitively. Therefore, we should at least be careful that the compensation demanded in the name of securities regulation to the injured class is indeed limited to their real injuries, lest there be excessive deterrence. For reasons explored elsewhere, I suspect that the prevailing compensatory scheme is unnecessarily generous to those who fall into the plaintiff class, making the self-fulfilling prophecy concern an especially serious one. ${ }^{57}$

${ }^{54}$ See supra note 36 (discussing cases in which deceiving another audience was the primary objective).

${ }^{35}$ See, e.g., Basic Inc. v. Levinson, 485 U.S. 224, 240 n.17 (1988) ("[W]e think that creating an exception to a regulatory scheme founded on a prodisclosure legislative philosophy, because complying with the regulation may be 'bad for business,' is a role for Congress, not this Court."); Heit v. Weitzen, 402 F.2d 909, 913 (2d Cir. 1968) ("Rule $10 \mathrm{~b}-5$ is violated whenever assertions are made ... in a manner reasonably calculated to influence the investing public, e.g., by means of the financial media ..., if such assertions are false or misleading or are so incomplete as to mislead irrespective of whether the issuance of the [press] release was motivated by corporate officials for ulterior purposes." (quoting SEC v. Texas Gulf Sulphur Co., 401 F.2d 833, 862 (2d Cir. 1968))).

${ }^{56}$ The indirect costs of too much candor is well explored in Edmund W. Kitch, The Theory and Practice of Securities Disclosure, 61 BROOK. L. REV. 763 (1995). See also San Leandro Emergency Med. Group Profit Sharing Plan v. Philip Morris Cos., 75 F.3d 801, 809-10 (2d Cir. 1996) ("We are concerned ... about interpreting the securities laws to force companies to give their competitors advance notice of sensitive pricing information.").

${ }^{57}$ See Donald C. Langevoort, Capping Damages for Open-Market Securities Fraud, 38 ARIz. L. REV. 639, 663-64 (1996) ("There is little doubt that courts have fashioned damage remedies in open-market fraud cases on the assumption that all frauds have victims, and all victims deserve full compensation. But it is too easy to lose sight of the fact that in the capital marketplace, questions of what constitutes fraud, how to prove it, and who is really a victim have no precise answers."); see also Janet Cooper Alexander, Rethinking Damages in Securities Class Actions, 48 STAN. L. REV. 1487, 1487 (1996) (arguing that damages in class-action securities suits are misaligned with the goals of securities litigation); Arlen \& Carney, supra note 19, at 694 (arguing that enterprise liability results in large wealth transfers from one group of innocent investors to another that are inconsistent with the goal of optimal loss spreading and that the goal of just compensation cannot justify enterprise liability because the burden of the liability ultimately falls on innocent shareholders); Paul G. Mahoney, Precaution Costs and the Law of Fraud in Impersonal Markets, 78 VA. L. REV. 623, 625 (1992) (arguing that the fraud-on-the-market theory "either impose[s] additional liability without additional social benefit, or divide[s] up a fixed recovery among a greater set of investors to the 
There is a related message about vicarious liability. Arlen and Carney argue that if selfish last-period behavior is at the root of most predictable forms of fraud on the market, then vicarious liabilitywhich visits liability on innocent shareholders of the firm-makes little sense. ${ }^{58}$ That is true. On the other hand, if some more sizable category of frauds really are business-motivated, then vicarious liability (at least if in an optimal amount) has far more to recommend it. ${ }^{59}$

\section{EXTENDING THE ECONOMIC ANALYSIS: THE PROBLEM OF INFORMATION FLOW}

\section{A. The Problem of Corporate Knowledge}

One subject on which there is substantial agreement over the full range of organization studies is that "upward" information flow poses a challenge for coherent corporate decisionmaking. ${ }^{60}$ Information is highly decentralized in business organizations. Especially when we focus on information and inferences that are not readily quantifiable-for example, customer reactions to new products, how well products are proceeding through the research and development pipeline-relatively low- or mid-level managerial personnel will have

detriment of those investors who require recovery in order to minimize precautiontaking"). The primary reasons are that most settlements and judgments are funded out of other innocent investors' pockets, rather than those of the primary wrongdoers, and the measure of damages fails to account for the windfall gains that many nonculpable investors receive from the fraud.

${ }^{53}$ See Arlen \& Carney, supra note 19, at 720 (arguing that holding the agent rather than the corporation liable for fraud on the market will provide a more just and effective deterrent).

${ }^{59}$ It seems clear that managers-boards of directors as well as insiders-would be sensitive to the risk of firm liability in making judgments about whether to lie in the interest of shareholders in merger, product development, and other "competitive" situations. Given the conflict of interest, however, Arlen and Carney are clearly right in seeing the need for agent liability as well.

${ }^{\infty}$ Information flow is a major concern in Kenneth Arrow's analysis of organizations. See KENNETH J. ARROW, THE LIMITS OF ORGANIZATION 33-43, 33 (1974) (stating that " $[t]$ he purpose of organizations is to exploit the fact that many (virtually all) decisions require the participation of many individuals for their effectiveness" and discussing the costs of communication channels as influenced by activities of the individual rather than the collection of information). For a more conventional economics perspective, emphasizing how informational asymmetry can be combatted in principalagent relationships within the firm, see PAUL MILGROM \& JOHN ROBERTS, ECONOMICS, ORGANIZATION AND MANAGEMENT 100-03 (1992), and WILIIAMSON, supra note 2. See also MERRITT B. FOX, FINANCE AND INDUSTRIAL PERFORMANCE IN A DYNAMIC ECONOMY 118 (1987) ("Ideas relating to the ... financial decisions of top management . ... are likely to be processed as they make their way toward the top managers of a firm."). 
the most immediate access to useful information. ${ }^{61}$ Corporations must devise some kind of communications system that enables important data to move upward to the proper decisionmaker, without causing all information of any arguable relevance to be moved to the desks of a sequence of busy supervisors. Corporate hierarchies serve this role, ${ }^{62}$ with varying systems of routines, norms, and philosophies to customize the information flow in any given firm. One common system is to teach managers to distinguish between the unusual and the usual, and limit information flow to the former. ${ }^{63}$ The currently celebrated norm of "participatory management" is another way of addressing the problem. ${ }^{64}$

The difficulty, of course, is that if material information must pass through a number of relay points in a hierarchy, the message can change (and lose accuracy) in the process. One need not assume any systematic cognitive bias at all. As the children's game of telephone inevitably illustrates, the mere act of retransmission makes it increasingly probable that the final message will not be the same as the one first sent. But economists and others assume that moral-hazard problems are severe here: Subordinate managers will be tempted to vary the message to conform to their self-interest. ${ }^{65}$

${ }^{61}$ See, e.g., Jane E. Dutton et al., Reading the Wind: How Middle Managers Assess the Context for Selling Issues to Top Managers, 18 STRATEGIC MGMT. J. 407, 407 (1997) ("It is often middle managers rather than the top managers who have their hands on the 'pulse of the organization." ").

${ }^{62}$ See generally Roy Radner, Hierarchy: The Economics of Managing, 30 J. ECON. LITERATURE 1382, 1387-1401 (1992) (discussing corporate hierarchies).

6s See id. at 1403 (describing the reporting rule of "management by exception").

${ }^{64}$ See Stephen M. Bainbridge, Participatory Management Within a Theory of the Firm, 21 J. CORP. L. 657, 680-96 (1996) (explaining the economic function of participatory management in the context of the theory of the firm). By giving lower-level managers and employees a role in company deliberations, more effective communication occurs. See $i d$. at 692 (noting that participatory management encourages "team spirit" and commitment to the group which, in turn, encourages productivity).

${ }^{65}$ See, e.g., ARROw, supra note 60, at 75 ("The efficiency loss due to informational overload is increased by the tendency in that situation to filter information in accordance with one's preconceptions."); RICHARD M. CYERT \& JAMES G. MARCH, A BEHAVIORAL THEORY OF THE FIRM 81-82, 109-10 (1963) (considering the effects of "both conscious and unconscious bias in expectations" on information); Dutton et al., supra note 61 , at 409 (stating that "people tend to control . . . information about themselves that will affect others' perceptions of them"); Martha S. Feldman \& James G. March, Information in Organizations as Signal and Symbol, 26 ADMIN. SCI. Q. 171, 176 (1981) ("Information is gathered and communicated in a context of conflict of interest and with consciousness of potential decision consequences. Often, information is produced in order to persuade someone to do something."); R. Joseph Monsen, Jr. \& Anthony Downs, A Theory of Large Managerial Firms, 73 J. POL. ECON. 221, 236 (1965) (concluding that "[m] anagers are 'economic men' who desire to maximize their own lifetime 
We should pause here to appreciate the full extent of the difficulty. The employees with the most immediate access to basic information are almost always line personnel with a range of operational duties, not just the role of informational monitor. Salespeople, for instance, have the best sense of customer attitudes. The combination of operational responsibilities and reporting duties creates an obvious conflict of interest. Compensation is often subjective and set by the immediate supervisor $^{66}$ (though sales is one area where performancebased compensation through commissions and quota systems is commonplace). For that reason alone, the natural reporting temptation is to transmit information in a way that minimizes the potential for blaming oneself for bad news, and to convey as much good news as possible to the extent that the information can be attributed to the source-consistent, of course, with a general desire to have a reputation for credibility with one's superiors. ${ }^{67}$ A further complication comes from the organization of many managers into teams, with no clear assignment of reporting responsibility to a particular member and ready excuses for treating the handling of bad news as a teammate's problem, rather than one's own.

The highly situational incentive to distort is exacerbated by the promotion and termination structures commonly found in large corporations. Especially for junior managers on the executive track, there is a rapid rotation of responsibilities. Rarely does one stay in one role for more than two years, and tangible evidence of skill and loyalty must be demonstrated repeatedly to justify promotion and

incomes" and that large firms develop bureaucratic structures that "tend to ... provide biased information to top management which reflects its own desires and ideas too strongly"). Jack Coffee has explored the information-flow problem as it relates to the potential for concealing corporate criminal activity. See Coffee, supra note 4, at 113147 (noting that adverse information relating to contingent liabilities appears not to reach the board until a crisis of scandal has become unavoidable); see also STONE, supra note 4, at 201-09 (discussing the corporation's information net). On insider trading and information flow, see Robert J. Haft, The Effect of Insider Trading Rules on the Internal Efficiency of the Large Corporation, $80 \mathrm{MICH}$. L. REV. 1051 (1982).

${ }^{66}$ Noteworthy here, as recognized even in conventional economic analysis, is the tendency to report to the boss what one perceives the boss wants to hear. See Canice Prendergast, $A$ Theory of "Yes Men", 83 AM. ECON. REV. 757, 769 (1993) ("If workers are rewarded on a subjective basis, they may distort their behavior toward what they feel their superiors want to hear.").

${ }_{67}$ Obviously, bad news that will be discovered shortly anyway cannot be concealed without paying a price in terms of future credibility. But bad news comes in many different guises; some may not be discovered for some time to come, and may be quite ambiguous in causal terms when it does. In these situations, impression management can have its desired effect. 
avoid termination or a career slowdown. This places special importance on the need to accentuate the positive and to distort bad news, and introduces a clear-cut long-term/short-term bias. ${ }^{68}$ To an ambitious manager facing a series of such "probationary crucibles," adverse information that would taint his or her candidacy but will not be realized more broadly within the organization until that manager has either moved up or out-at a time when any attribution of personal responsibility is either impossible or unlikely because so many possible causes intervene over time-should be concealed or distorted.

As economists are quick to point out, none of this comes as a surprise, ${ }^{70}$ and thus efficiency-driven firms must try to counter the problem. There are techniques to try to induce more accurate reporting. The prevailing system of accounting and auditing, for example, has, as one function, the creation of an internal financial-control system that is independent of the moral hazard of line-personnel reporting. Such systems, however, are expensive and workable only with respect to certain kinds of independently verifiable data (and are probably more subjective and subject to failure than we would like to think)." Other monitoring interventions are also possible, but again tend to

${ }^{6}$ See Elizabeth A. Mannix \& George F. Loewenstein, The Effects of Interfirm Mobility and Individual Versus Group Decision Making on Managerial Time Horizons, 59 ORG. BEHAV. \& HUM. DECISION PROCESSES 371, 374 (1994) ("High levels of [interfirm] mobility uncouple managers' personal gains from the long-term performance of the company for which they are employed at a particular point in time."). This is especially true in organizations that are team-based, where the managers who have instituted a poor policy are elsewhere when the impact is felt and there is no good mechanism for assigning blame retrospectively.

${ }^{69}$ ROBERT JACKAIL, MORAL MAZES 40 (1988). Jackall's work is very interesting in this regard, emphasizing the complex relationship among promotion patterns, information flow, and moral judgments. His relatively pessimistic conclusion is that the interplay of these factors biases the corporate hierarchy toward those who are relatively plastic in their ethical thinking - good team players who know how to manage information and not threaten teammates and superiors in how they handle what they observe. See id. at 56 (describing the essential characteristics of the "team" player); see also Frederick B. Bird \& James A. Waters, The Moral Muteness of Managers, CAL. MGMT. REV., Fall 1989, at 73, 76 (noting that managers' interactions are influenced by their concerns that "moral talk will threaten organizational harmony, organizational efficiency, and their own reputation for power and effectiveness").

${ }^{70}$ For an overview, see Radner, supra note 62.

"Indeed, even in accounting-where the monitoring structure is most formalized-the risk of "audit failures" for a variety of reasons (not simply because the misbehavior was well concealed, but because of compromised independence, conflict of interest, and cognitive bias) is far from trivial. See Timothy J. Fogarty, The Imagery and Reality of Peer Review in the U.S.: Insights from Institutional Theory, 21 ACCT. ORG. \& SOC'Y 243, 251 (1996) (addressing the discrepancies between promises of peer reviews and their actual delivery by accountants). 
be costly both in terms of personnel and morale; overly intrusive monitoring may well be inconsistent with other important traits needed in a competitive environment, such as trust, aggressiveness, and risk-taking. ${ }^{72}$ One can also try to encourage multiple, independent information tracks. Though these can be useful, they simply increase ambiguity if differing interpretations of the same subjects filter upward, and are no less subject to selfish manipulation.

Thus, it is not surprising that most corporations opt for some variation of the traditional hierarchical structure, which depends on a mix of contractual incentives and cultural norms to induce appropriate behavior at each level. Each superior monitors both the operation and the information-reporting performance of the subordinate manager, and adjusts compensation and promotion accordingly. There is likely to be much emphasis on "responsiveness" and endless team meetings and cultural displays about the need for accurate and timely information flow. But one cannot be overly optimistic about the outcome: The moral-hazard problem can be dampened through structure and contract but not eliminated. Consider the position of a manager who both supervises a team and reports to a series of higherlevel managers. In seeking accurate information from subordinates, she must keep in mind that the information may not reflect well on her to the extent that it is subject to retransmission upward. Under these circumstances, the supervisor may communicate that there are certain things she wants to hear and certain things she does not. ${ }^{74}$ Indeed, she may well encourage subordinates to keep negative information from her in order to preserve the ability to deny responsibility should problems later be uncovered. ${ }^{75}$ This could be accomplished

${ }^{72}$ See Carol M. Rose, Trust in the Mirror of Betrayal, 75 B.U. L. REV. 531, 540-41 (1995) ("[P]eople do not like to be monitored. They may well mistake monitoring and questioning for distrust ...."); Sim B. Sitkin \& Darryl Stickel, The Road to Hell: The Dynamics of Distrust in an Era of Quality, in TRUST IN ORGANIZATIONS 196, 209 (Roderick M. Kramer \& Tom R. Tyler eds., 1996) (" $[\mathrm{H}]$ ighly formalized management control systems can lead to escalating distrust...."). The point made in this literature is that monitoring is a signal of distrust, which both affects the subordinates' level of commitment, and shifts time and attention to managing the impressions of the monitor rather than doing "real work."

${ }_{73}$ Indeed, if the monitors observe operational success (for example, profitability), the chance of disciplining a manager based on faulty information reporting may be minimal.

${ }^{74}$ See Prendergast, supra note 66, at 757 (illustrating incentives for workers to conform to the opinions of their superiors).

${ }^{75}$ See, e.g., Larry D. Browning \& Robert Folger, Communication Under Conditions of Litigation Risk: A Grounded Theory of Plausible Deniability in the Iran-Contra Affair, in THE LEGALISTIC ORGANIZATION 251, 251-52 (Sim B. Sitkin \& Robert J. Bies eds., 1994) 
through an explicit injunction, or, more likely, through the cultivation of a reputation for "shooting the messenger"-acting punitively against subordinates who do not act with discretion when transmitting accurate, adverse information upward. ${ }^{76}$

Even if a senior manager made a credible statement that she wanted accurate information reporting (and was prepared to enforce the rule through sanctions), it is unlikely that this would necessarily trigger conforming behavior below. The problem of termination and compensation remains in an environment of informational asymmetry where monitoring reporting accuracy is often impossible. In other words, we have a large-scale replication of Arlen and Carney's lastperiod problem ${ }^{77}$ in each nested layer of the hierarchy. To the extent that any given employee fears the possibility of being fired or deadended in light of a candid portrayal of the situation (a constant in fast-track managerial pyramids), distortion or concealment becomes a dominant strategy regardless of long-term promises, threats, or reputational incentives. ${ }^{78}$

(discussing the building of a wall around President Reagan by subordinates so he could plausibly deny liability); Jack Katz, Concerted Ignorance: The Social Construction of Cover-Up, 8 URB. LIFE 295, 298-305 (1979) (discussing how cover-ups are established and maintained in large scale organizations through "concerted ignorance" by superiors and subordinates).

${ }^{76}$ Here we once again encounter a particular problem with respect to information that is either ambiguous or incomplete (the latter being commonplace when there is substantial diffusion of responsibility within the firm). The employee does not know for sure whether it is serious, and runs the risk of considerable blame if she raises it and it turns out to be groundless. In that situation, employees may choose to withhold key pieces of information that, if made available to the higher-ups, could be pieced together and dealt with.

${ }_{77}$ See supra notes 40-44 and accompanying text.

${ }^{73}$ Cf. Keith C. Brown et al., Of Toumaments and Temptations: An Analysis of Managerial Incentives in the Mutual Fund Industry, 51 J. FIN. 85, 90-93 (1996) (offering evidence of comparable short-term opportunism notwithstanding reputational incentives). We need not assume that these distortions are in bad faith. One of the most noted theorists in this area, Chris Argyris, argues that the desire to avoid unpleasant confrontation and maintain positive relationships in organizations ultimately leads to organizational defensiveness: Leaders communicate (implicitly) that certain matters are "undiscussable," and information flow thereby becomes skewed as communication both up and down the organization chart ayoids treating these issues. Problems therefore disappear from managerial awareness until crisis, and effective corporate learning is frustrated. See CHRIS ARGYRIS, OVERCOMING ORGANIZATIONAL DEFENSES 14-31 (1990) (addressing how defensive reasoning affects organizations); see also ARGYRIS \& SCHöN, supra note 8, at 15-17 (discussing organizational learning). For an attempt to integrate Argyris's theory with economic theory, see Harvey Leibenstein \& Shlomo Maital, The Organizational Foundations of X-Inefficiency, 23 J. ECON. BEHAV. \& ORG. 251 (1994). 
The image that we are left with, then, is that the forward-looking information package that arrives at the top of the hierarchy after being filtered through multiple layers-the mosaic of data and inference from which forward-looking corporate disclosures must be drawn-is likely to be more uncertain in its accuracy than might appear at first glance. Positive information will move more quickly to the top, with the primary problem in assessing it being the possibility of overstatement, and excessive and conflicting claims of credit. Negative information will travel more slowly, if at all, and will be more subject to skewing. On average, a natural optimistic bias results. And the problem of distortion becomes most severe in companies that face substantial adverse shocks to their environments. ${ }^{79}$

We should therefore be sympathetic to the plight of the senior executive charged with disclosure responsibilities. There is evidence in the literature that senior executives do habitually discount the veracity of information that moves upward, especially when it has a positive spin. ${ }^{80}$ But that discount is rough and imprecise, and thus of little aid in achieving disclosure accuracy. Forward-looking disclosure or disclosure of facts, the import of which are largely predictive, must often be made with less-than-complete confidence of their accuracy, with the nagging sense that with more time, doubts about data quality might naturally diminish. From time to time, senior executives will discover, much too late, that the truth is indeed quite different from what they have been led to believe. To be sure, senior executives cannot explicitly acknowledge this. Part of the essential dramaturgical role of senior managers is to communicate confidence and control over their environment, and as we have seen, many management theorists believe that effective corporate disclosure must reflect a comparable level of confidence in control, if not performance, by the senior management group. ${ }^{81}$ Thus, even putting aside the possibility that those top managers have their own selfish reasons to distort, there is a substantial risk of a mismatch between what they say and

${ }^{79}$ According to the organizational-decline literature, see supra note 50, one common tendency in firms under financial stress is the centralization of authority at the top, thereby narrowing of lines of communication. See Sutton, supra note 50, at 223-26 (describing "rigidity" effects of danger). Sensing a last period, employees may then abet this tendency by either withdrawing or engaging in extremely self-protective communications.

${ }^{80}$ See Haft, supra note 65, at 1053-54 ("Superiors may reduce distortion by counterbiasing or discounting the content of the message by the self-interest that they perceive the sender to have in the message."), and sources cited therein.

${ }^{81}$ See supra notes $49-50$ and accompanying text. 
what, once a retrospective look at what all those in the organization actually knew or sensed is undertaken, was "known" by others in the firm.

\section{B. Some Legal Implications}

There are some interesting implications for corporate and securities law simply from recognizing the dynamics of information flow. The dominating question is whether a company can be held liable for a violation of Rule 10b-5 upon a showing that even though the individual managers who formulated the disclosure were not aware of information that would cause them to doubt its accuracy, such information was possessed by others in the company (who may or may not have known that disclosure was being made). ${ }^{82}$ Rule $10 \mathrm{~b}-5$ has a scienter requirement, which in the eyes of most courts can be satisfied by a showing of either knowledge or recklessness on the defendant's part. $^{83}$

${ }^{82}$ Arguably, it is something of an open question as to whether companies can be held liable at all under Rule $10 \mathrm{~b}-5$ as primary violators (as opposed to controlling persons under section 20(a) of the Securities Exchange Act, 15 U.S.C. $\$ 78 t(a)$ (1994)). By most accounts, they can, if by nothing else than reference to the definition of "person" in section $3(a)(9)$ of the Act, which refers specifically to juristic persons. See id. $\S 78 c(a)(9)$ ("The term 'person' means a ... company ...."). Since corporations almost by necessity speak through agents, the natural construction of section $10(\mathrm{~b}), i d$. $\S 78 \mathrm{j}(\mathrm{b})$, and section $3(\mathrm{a})(9), i d . \$ 78 \mathrm{c}(\mathrm{a})(9)$, read together, makes it possible for corporations and other business entities to violate the antifraud provision directly. See SEC v. Management Dynamics, Inc., 515 F.2d 801, 812 (2d Cir. 1975) ("Congress evidently intended that a corporation might be liable in some instances as a 'person'; and this can only be by virtue of agency principles, since a corporation can act only through its agents."). For this reason, we shall assume that corporations can be primary violators even though they speak through their agents, notwithstanding the suggestion in Central Bank v. First Interstate Bank that section 10(b) does not prohibit secondary forms of liability. See 511 U.S. 164, 184 (1994) ("The fact that Congress chose to impose some forms of secondary liability, but not others, indicates a deliberate congressional choice with which the courts should not interfere."); Donald C. Langevoort, Words from on High About Rule 10b-5: Chiarella's History, Central Bank's Future, 20 DEL. J. CORP. L. 865, 893-96 (1995) (reformulating fraud cases formerly understood as issues of respondeat superior liability into terms of direct-entity liability).

${ }^{83}$ See Ernst \& Ernst v. Hochfelder, 425 U.S. 185, 201 (1976) (“\$ 10(b) was addressed to practices that involve some elements of scienter and cannot be read to impose liability for negligent conduct alone."); COX ET AL., supra note 11, at 697-709 (commenting that Hochfelder only rejected negligence from sufficing for liability under Rule $10 \mathrm{~b}-5$ without further defining scienter). The prevailing approach today is to treat recklessness as a subjective standard: There must be some awareness of the risk that the disclosure is false or misleading, not simply an extreme departure from the standard of care. See, e.g., Sanders v. John Nuveen \& Co., 554 F.2d 790, 793 (7th Cir. 1977) ("We believe 'reckless' in these circumstances comes closer to being a lesser 
It is easy enough doctrinally to make the affirmative case, simply by invoking basic agency-law principles that attribute all information acquired by any company employee acting in the scope of her authority to the company itself. ${ }^{84}$ Agency law contains a "corruption" exception for situations where the employee is acting in a purely selfserving fashion, but this would not apply to the normal kinds of business-related information we have been discussing. ${ }^{85}$ Outside of the securities laws, a number of criminal and civil cases have concluded that one need not identify any individual manager who is culpable in order to have firm culpability under a "knowledge" standard: Aggregation of knowledge is an acceptable basis for liability. ${ }^{86}$ No cases, however, explicitly recognize such a theory under Rule 10b-5, and many cases, indirectly at least, seem to assume the contrary-that liability follows only if the human beings responsible for the disclosure were aware of the falsity or recklessly disregarded the truth. ${ }^{87}$

form of intent than merely a greater degree of ordinary negligence. We perceive it to be not just a difference in degree, but also in kind.").

84 See, e.g., RESTATEMENT (SECOND) OF AGENCY $\$ 272$ (1958) (mandating general attribution of knowledge). For one of the few academic discussions of this issue, see Craig L. Griffin, Comporate Scienter Under the Securities Exchange Act of 1934, 1989 BYU L. REV. 1227.

${ }^{85}$ See RESTATEMENT (SECOND) OF AGENCY $§ 282$ (1958) (providing that knowledge of the agent is not attributed to the principal if the agent is acting adversely to the principal when the agent obtains or uses the knowledge).

${ }^{86}$ See, e.g., Nordstrom, Inc. v. Chubb \& Son, Inc., 54 F.3d 1424, 1434 (9th Cir. 1995) (finding that a good-faith defense in a fraud case is only available where the directors did not induce the acts constituting the violation); Bank of New England v. United States, 821 F.2d 844, 850 (1st Cir. 1987) ("A collective knowledge instruction is entirely appropriate in the context of corporate criminal activity."); C.I.T. Corp. v. United States, 150 F.2d 85, 94 (9th Cir. 1945) ("In order that concealment of the property of a bankrupt may be ... a crime, it must be 'knowingly and fraudulently' concealed ...."). This is not the case, however, if the standard is based on willfulness. See SABA v. Compagnie Nationale Air France, 78 F.3d 664, 668 (D.C. Cir. 1996) (finding that lack of judgment and common sense by employees does not constitute willful misconduct). For a recent argument that this line of authority is both misguided and based on a misreading of the seminal case law, see Thomas A. Hageman \& Joseph Grinstein, The Mythology of Aggregate Corporate Knowledge: A Deconstruction, 65 GEO. WASH. L. REV. 210 (1997).

${ }^{87}$ See, e.g., First Equity Corp. v. Standard \& Poor's Corp., 690 F. Supp. 256, 260 (S.D.N.Y. 1988) ("A corporation can be held to have a particular state of mind only when that state of mind is possessed by a single individual."). Most cases that deal with scienter do so on preliminary motions to dismiss for failure to plead facts giving rise to a sufficient inference of scienter. Here, a court may well choose to allow the knowledge of subordinates to suffice even if the court believes that a showing of knowledge by the person responsible for the disclosure would be required at trial before liability could be imposed. For a case allowing a complaint to stand on such grounds, although hinting that a showing that the high-level officials were not actually aware of 
The possibility that information-flow distortion can produce inaccurate disclosures by high-level officials helps illuminate this policy issue. To the extent that either the compensatory goal of making investors-who somehow have relied on misinformation-whole, or the deterrence goal of preventing misinformation from affecting the market, is compelling, then a rule requiring that the speaker act with scienter would be counterproductive. Even if the compensatory goal in fraud-on-the-market cases is questionable, ${ }^{88}$ the deterrence goal is undeniably crucial to the ultimate goal of producing accurate stock prices. $^{89}$ One can also assume that were this rule well understood within firms, the tendency to withhold deliberately damaging information from superiors as a way of protecting both themselves and the firm would be stronger. ${ }^{90}$ Superiors would have one more reason to prefer the "plausible deniability" that comes from avoiding full information. ${ }^{91}$ That is hardly a desirable outcome.

At the same time, of course, one should also be aware of the costs associated with the aggregation rule, costs all ultimately borne by the firm's shareholders. De facto, this means that senior executives cannot prevent corporate liability simply by behaving honestly as a group, but instead must implement the best available internal informationcontrol devices to manage the liability risk. However, such protection. will only be partial; breakdowns are inevitable in the best of systems.' In essence, then, Rule $10 \mathrm{~b}-5$ would operate for firms in something more akin to a negligence standard in terms of the precaution costs it generates. Some law-and-economics scholars have treated this scienter-based liability as if it generates no such costs. ${ }^{92}$ That treatment is

the problem would preclude issuer liability at trial, see Steiner $v$. Unitrode Corp., 834 F. Supp. 40, 45 (D. Mass. 1993).

${ }^{83}$ See supra note 57 and accompanying text.

${ }^{89}$ See Marcel Kahan, Securities Law and the Social Costs of Inaccurate Stock Prices, 41 Duke L.J. 977, 1028 (1992) (discussing the various ways in which stock-price inaccuracies detrimentally affect the market and management's behavior).

${ }^{90}$ See Coffee, supra note 4, at 1119 (discussing the rationale of and the solutions to "defensive" corporate misbehavior).

"See supra note 75 and accompanying text. In this regard, Jennifer Arlen has noted that too easy an attributional form of corporate criminal liability can lead corporations to underinvest in monitoring and detection mechanisms. See Jennifer Arlen, The Potentially Perverse Effects of Corporate Criminal Liability, 23 J. LEGAL STUD. 833, 843 (1994) (discussing the effects that different schemes of imposing criminal corporate liability will have on corporate enforcement expenditures). Of course, this would not necessarily deter firms from monitoring in order to detect misconduct that was about to occur or still in the process of occurring.

${ }^{92}$ Cf., e.g., EASTERBROOK \& FISCHEL, supra note 1, at 339-44 (arguing that the scienter requirement encourages more accurate enforcement, but also acknowledging that 
probably inaccurate, given the fuzziness of securities-law responsibilities and the palpable risk of judicial error. ${ }^{93}$ An aggregation rule makes all the more clear what has been expressed in Part I-that Rule $10 \mathrm{~b}-5$ generates a surprisingly large number of hidden costs that must be added to the calculus when assessing desirable policy. ${ }^{94}$

To the extent that the law continues its apparent preference for requiring actor-level scienter, however, another message becomes clear: Recklessness has a particularly important practical role to play in the application of Rule $10 \mathrm{~b}-5$. Recall once again the likely sense that senior executives have when dealing with fast-moving corporate events for which they lack primary access to information. They will receive information, perhaps from multiple, and thus conflicting, sources that may well have become distorted in transmission. In other words, senior executives have some basis for disclosure, but may be less than fully confident of its accuracy. A public statement that relies on this internal information but fails to convey the bases for doubt or the conflicting information available to the speaker may not be a knowing form of deception-in some ways, it is the speaker's best estimate of the situation as presented from within the organization. ${ }^{95}$ However, one can readily imagine particular cases in which enough conscious doubt has been suppressed that the resulting disclosure is culpably misleading, and recklessness would provide the clearest way of characterizing the underlying state of mind. ${ }^{96}$

The agency-cost information-distortion phenomenon may also help explain some well-known judicial decisions in securities law. As

if section $10(\mathrm{~b})$ does generate precaution costs, their own analysis would have to change).

${ }^{99}$ See Mahoney, supra note 57, at 625 ("[T] he problem of applying fraud doctrine to impersonal markets extends beyond securities law, and taken to its extreme, [the fraud-on-the-market theory] could swallow up a considerable amount of the common law of fraud."). Because scienter can be proven circumstantially, it is always possible that the corporate executive's disregard of red flags, considered in hindsight, will be treated by the courts as recklessness, when, in reality, it might have been, at most, negligence.

See supra notes 56-57 and accompanying text.

${ }^{95}$ Here, on the assumption regarding actor intent-based liability, there would be no cause for imposing liability. On the other hand, if the law were to choose a broad attribution rule, this would not be an issue: The corporation would be liable simply via the attribution of knowledge from other employees.

${ }^{96}$ Consistent with the subjective test for recklessness, this is the situation in which the executive is consciously unsure of the accuracy of his statements, but speaks confidently nonetheless. For a recent survey of the law in this area, see William $H$. Kuehnle, On Scienter, Knowledge, and Recklessness Under the Federal Securities Laws, 34 Hous. L. REV. 121 (1997). 
noted earlier, the seminal fraud-on-the-market decision under Rule 10b-5 is SEC $v$. Texas Gulf Sulphur Co. ${ }^{97}$ There, Texas Gulf Sulphur ("TGS") was in possession of core drilling samples that suggested that certain property in Ontario might contain extremely valuable mineral deposits; yet a TGS press release dampened the investor enthusiasm that had developed as rumors leaked out about the possible find. ${ }^{98}$ Thus, this case is one of the less common "good news" concealment cases under Rule 10b-5. One of the fascinating questions that remains is why TGS would have taken the actions that it did. A common response is that the company was seeking to buy up more land and wanted to keep potential sellers unaware of the value of their property, but this seems questionable. The rumors were already circulating, and the press release hardly denied the find. ${ }^{99}$ Few of the owners of land coveted by TGS would be fooled into selling their land at less than full value in this setting. There is an intriguing alternative explanation: To the extent that top company officials had some reason, based on past experience, to be skeptical of the internal optimistic reports, a natural and good-faith response would be one that layered the disclosure with an abundance of caution in order to reduce litigation exposure should the actual results turn out to be disappointing. The TGS press release, in other words, might simply have been the product of managers who, like many of their peers, have doubts about the heralds of good news that commonly percolate up from the operating divisions, and habitually apply a discount to these messages. ${ }^{100}$

\section{BIASED INFERENCE AND CORPORATE CULTURES}

\section{A. The Sources of Bias}

The organizational and social environment in which the decision maker finds himself determines what consequences he will anticipate, what ones he will not; what alternatives he will consider, what ones he will ignore. In a theory of organization these variables cannot be treated as unexplained independent factors, but must themselves be determined and predicted by the theory.

${ }^{97} 401$ F.2d 833 (2d Cir. 1968); see supra note 27 and accompanying text.

${ }^{98}$ See Texas Gulf Sulphur, 401 F.2d at 845.

${ }^{99}$ See id. at 844-46.

${ }^{100}$ See supra note 80 and accompanying text.

101 JAMES G. MARCH \& HERBERT A. SimON, ORGANIZATIONS 160 (2d ed. 1993); see also Mark C. Suchman, Managing Legitimacy: Strategic and Institutional Approaches, 20 
As this quotation from James March and Herbert Simon's seminal work on organizational behavior implies, there are crucial differences in how organization theorists who do not work from the standard economic paradigm view organizational cognition as compared to more orthodox economists. In many ways, these differences boil down to an emphasis on organizational culture that is distinct from the immediate performance demands of the profit-seeking enterprise. Culture-the norms, routines, and shared understandings and expectations of those who participate in the firm's activities ${ }^{102}$-is central because performance demands are often highly ambiguous once basic success has been achieved and the set of routines supporting the firm's basic technology is in place. In the face of external ambiguity with respect to further strategic decisionmaking, ${ }^{103}$ organizations may turn inward to find explanations for action and the pursuit of legitimacy.

Some of this inwardness has a perfectly rational agency-cost explanation. ${ }^{104}$ Basic technological success creates vested political interests within the firm that are upset by strategic or technological change. As in all aspects of society, process and routine are inherently conservative. As March and Simon suggest, however, culture also has a strong cognitive dimension that does not simply reflect the self-interests of individual power bases. A basic premise in work on organizational behavior is that institutions develop belief systemsshared ways of interpreting themselves, their environments, their pasts, and their prospects. These belief systems are functionally important because they facilitate interaction and communication between managers and employees, simplifying the task of coordinating

ACAD. MGMT. REV. 571, 573 (1995) (discussing the importance of social values in the organizational structure).

${ }^{102}$ From among the vast literature on corporate cultures, see JOANNE MARTIN, CULTURES IN ORGANIZATIONS (1992).

${ }^{103}$ According to one review of the available literature, the fundamental challenge faced by managers, and hence their organizations, is "that their information worlds are extremely complex, ambiguous, and munificent." Walsh, supra note 20, at 280; see also Frances J. Milliken \& Theresa $\mathrm{K}$. Lant, The Effect of an Organization's Recent Performance History on Strategic Persistence and Change: The Role of Managerial Interpretation, in 7 ADVANCES IN STRATEGIC MANAGEMENT 129, 152 (Paul Shrivastava et al. eds., 1991) (suggesting that "managers ... may ignore environmental changes, may be motivated to explain performance outcomes in ways that protect themselves, and may persist with outdated strategies, or even undermine the organizational properties that have produced success").

104 For an exploration of bureaucratic growth that incorporates both standard economics and psychological explanations, see Saul Levmore, Irreversibility and the Law: The Size of Firms and Other Organizations, 18 J. CORP. L. 333 (1993). 
the diverse activities of large numbers of people. The failure of company employees to operate on a shared set of assumptions about their environment makes internal negotiation difficult and coherent operations impossible. ${ }^{105}$ Equally important are useful belief systems that are essential to the task of gaining support from employees and other key constituents of the firm. ${ }^{106}$ Indeed, many theorists argue that the crucial job of top management is nurturing the optimal belief system. Jeffrey Pfeffer, for example, writes that management is essentially the art of providing "explanations, rationalizations, and legitimation for the activities undertaken in the organization." ${ }^{107}$ Similarly, Karl Weick and Richard Daft contend that "the job of management is to interpret, not to get the work of the organization done."108 This is not to say that all employees become true believers in all that management says or that corporate norms suggest. Consciously, some employees will often complain or criticize the corporate belief system. But few doubt that, on average (and even with respect to some of the apparent cynics), these belief systems are powerful normative influences once a coherent culture evolves.

We need not treat even this as a wholly noneconomic construct, of course. Economists have increasingly become interested in cultures as reputational mechanisms for generating trust within organizations and making the firm's external commitments more credi-

${ }^{105}$ See MARTHA S. FELDMAN, ORDER WTrHOUT DESIGN 136-37 (1989) (discussing the ability of routines "to organize work and produce results despite the fact that the participants ... do not appear to value ... the outcomes"). This is an extremely important point. Imagine two people who must work out a commercial relationship. The first task is to come to some common understanding of the existing situation, and then move on to understand the means necessary to carry out their mutual objective. That is often a difficult and time-consuming task. Add a third person, and so on, and the task becomes exponentially more complex. In a large organization, there are hundreds, perhaps thousands, of key stakeholders. If each transaction within the firm must be preceded by this process of mutual orientation and agreement, the ability to conduct intrafirm business will be slowed considerably. To the extent that a shared culture provides stock understandings, these same transactions will be facilitated, and with them, firm efficiency. For an example of the need to gain a common understanding in order to produce coherent corporate activity, see C. Marlene Fiol, Consensus, Diversity, and Learning in Organizations, 5 ORG. SCI. 403 (1993).

${ }^{106}$ See supra notes 49-50 and accompanying text.

${ }^{107}$ Pfeffer, supra note 49 , at 4.

${ }^{108}$ Karl E. Weick \& Richard L. Daft, The Effectiveness of Interpretation Systems, in ORGANIZATIONAL EFFECTIVENESS 71, 90-91 (Kim S. Cameron \& David A. Whetten eds., 1983). 
ble. ${ }^{109}$ The primary points of departure, however, are cognitive and behavioral. Cultures can have strong elements of myth in them; they do not depend on (and may find counterproductive) too strong a dose of reality. Myths reduce the fear and stress that uncertainty often generates. Consequently, there are strong arguments within the literature on organizational cognition that predictable biases operate within corporate belief systems in a way that cause managers to misperceive events and risks, allowing them in good faith to perpetuate an unrealistic belief system in the face of external stress. ${ }^{110}$ If so, we have another plausible explanation for deceptive corporate disclosure, with interesting legal implications. Disclosure will reflect not what an objective observer would see, but what someone embedded in the corporate culture would perceive.

To be sure, there are no fixed behavioral rules that inevitably blind corporate managers-the standard claim here is that there is a loose coupling between beliefs and productivity, not a complete separation. ${ }^{\text {"I }}$ Much information is sufficiently unambiguous that its mes-

${ }^{109}$ See David M. Kreps, Corporate Culture and Economic Theory, in PERSPECTIVES ON POSITIVE POLITICAL ECONOMY 90, 100-11 (James E. Alt \& Kenneth A Shepsle eds., 1990) (discussing reputational theory in corporate transactions).

${ }^{110}$ See sources cited supra note 20 (discussing organization-based perceptual biases); see also Marjorie A. Lyles \& Charles R. Schwenk, Top Management, Strategy and Organizational Knowledge Structures, 29 J. MGMT. STUD. 155, 170 (1992) (arguing that "organizational knowledge structures assume that there is a representation of complex events and their interpretations are stored in the collective knowledge of firms" and noting that "[s]trategic responses to new situations may be the result of generalizing from the existing knowledge structure"); William H. Starbuck, Congealing Oil: Inventing Ideologies to Justify Acting Ideologies Out, 19 J. MGMT. STUD. 3, 8 (1982) (describing studies that show managerial beliefs that depart substantially from objective measures of reality, sometimes falling into the category of the "utterly fantastic"); Starbuck \&e Milliken, supra note 20, at 36 (arguing that different perceptual filtering processes affect how executives "observe and try to understand their environments"). For specific examples, see Paul Shrivastava et al., Nonrationality in Organizational Actions, 17 INT'L STUD. MGMT. \& ORG. 90, 91-95 (1987) (discussing how corporate belief systems contributed to disasters for Texas Instruments, Citibank, and International Harvester), and Shaler A. Zahra \& Sherry S. Chaples, Blind Spots in Competitive Analysis, ACAD. MGMT. EXECUTIVE, May 1993, at 7, 9-21 (identifying six flaws in companies' analyses of their competitive market).

"I See Daniel A. Levinthal \& James G. March, The Myopia of Learning, 14 STRATEGIC MGMT. J., Special Issue, Winter 1993, at 95, 110 (1993) (noting pervasive learning biases, but also conceding that organizations can improve). Not surprisingly, psychologically oriented researchers and conventional economists debate over the ability of "cognitive defects" to persist, especially in competitive markets and among expert decisionmakers. See infra notes $165-95$. There are, however, two reasons why consideration of biases can fit reasonably well into the economist's framework, at least within the "bounded rationality" paradigm that has come to be widely accepted. See Conlisk, supra note 3, at 669 (providing four reasons to incorporate bounded rationality in 
sage is hard to distort. Even in the face of ambiguity, some managers, under some circumstances, will see risks more clearly, and some companies will do better than others at "debiasing." Bias is highly contextual, and I do not want to overstate the incidence of distortion in corporate perception. My claim is simply this: These biases are sufficiently well-accepted in both the theoretical and empirical literature that we should take them seriously as behavioral risks, even if we cannot determine their exact role in any given setting ${ }^{12}$ or estimate how often they will apply in general. Four such biases, discussed below, are worth particular attention. ${ }^{113}$

economic models). One is the counterintuitive but persuasive conclusion that many of these biases may be adaptive and efficient on average-something that helps explain their persistence even among experts. See Colin F. Camerer \& Eric J. Johnson, The Process-Performance Paradox in Expert Judgment: How Can Experts Know So Much and Predict So Badly?, in TOWARD A GENERAL THEORY OF EXPERTISE 195, 210 (K. Anders Ericsson \& Jacqui Smith eds., 1991) (noting that experts, in the face of contradictory evidence, tend to revise rather than abandon their configurational rules). The other is ample evidence that people and organizations do not learn from experience as well as the rational-actor model would predict. For people to learn from their mistakes, feedback must be both immediate and unambiguous-conditions that rarely apply in business settings. Hence, biases and illusions can persist. See, e.g., Ed Bukszar \& Terry Connolly, Hindsight Bias and Strategic Choice: Some Problems in Learning from Experience, 31 ACAD. MGMT. J. 628, 630 (1988) (suggesting that hindsight distorts a manager's understanding of past decisions); Jack Feldman, On the Difficulty of Learning from Experience, in THE THINKING ORGANIZATION, supra note 20, at 263, 271-79 (outlining factors that produce errors in learning from experience).

${ }^{112}$ There is a strong and justified concern that psychological explanations can be invoked too easily to explain "fiascos" in hindsight. The factual complexity of such settings makes empirical verification impossible. See, e.g., MARK BOVENS \& PAUL 'T HART, UNDERSTANDING POLICY FIASCOS 8-9 (1996) ("People tend to underestimate systematically the complexity of issues, the inconclusiveness of information and the general uncertainty which is caused by strategic interaction ...."); Baruch Fischhoff \& Ruth Beyth-Marom, Failure Has Many Fathers, 7 POL'Y SCI. 388, 391 (1978) (reviewing IRVING JANIS, VICTIMS OF GROUPTHINK (1972)) (“[P] eople consistently overestimate the predictability of past events once they know how they turned out.").

${ }^{113}$ The social-cognition literature tends to distinguish between two types of biases. Some are purely cognitive ("cold"). They exist simply to manage complexity and make action possible in a world of bounded rationality. See Philip E. Tetlock \& Ariel Levi, Attribution Bias: On the Inconclusiveness of the Cognition-Motivation Debate, $18 \mathrm{~J}$. EXPERIMENTAL SOC. PSYCHOL. 68, 70-74 (1982) (discussing the cognitive approach). Others are motivated ("hot"). These biases exist because they serve some adaptive function not grounded in rationality, and thus are the more likely source of mythic beliefs. See id. at 75-82 (discussing the motivational theories). In many cases, it is difficult to arrive at a single explanation. See id. at 84 . ("[T] he dichotomy between cognitive and motivational explanations will become increasingly blurred and difficult to discern as the two theoretical positions are refined."). 


\section{Cognitive Conservatism and Decision Simplification}

A well-documented tendency of people who must operate in noisy informational environments is to adopt heuristic forms of thought. Busy executives process extraordinarily large amounts of information in both making decisions and deciding what matters deserve further time and attention. Such processing must necessarily be simplified, sometimes oversimplified, to make the information manageable, lest the executive be overwhelmed by data and paralyzed by ambiguity. ${ }^{114}$

Commonly, people build schemas to provide them with "best available" interpretations. These include stock understandings of people and situations. When given enough motivation, people will revise their schemas to reflect new information. But processing limits lead to a bias against revision: The normal cognitive strategy is to construe information and events in such a way as to confirm prior attitudes, beliefs, and impressions. ${ }^{115}$ Like all biases, this "cognitive conservatism" occurs unconsciously. ${ }^{116}$

114 See Sara Kiesler \& Lee Sproull, Managerial Responses to Changing Environments: Perspectives on Problem Sensing from Social Cognition, 27 ADMIN. SCI. Q. 548, 549 (1982) (noting that large amounts of information often obscure the meaning of relevant information); Walsh, supra note 20, at 280-81 (discussing the "bewildering flow of information faced by managers"). One of the remarkable developments in economics during the last decade or so has been the growing recognition of the costs associated with cognitive attention, and, accordingly, the need to develop models of decisionmaking that recognize the tradeoffs that must be made. See, e.g., JOHN W. PAYNE ET AL., THE ADAPTIVE DECISION MAKER 70-116, 114 (1993) ("[S]trategy selection is the result of a compromise between the desire to make the most accurate decision and the desire to minimize effort."). For a review of the recent literature, see Conlisk, supra note 3, at 670-75.

115 See SUSAN T. Fiske \& SHElley E. TAYlor, Social Cognition 149-51, 150 (2d ed. 1991) ("Well-developed schemas generally resist change and can even persist in the face of disconfirming evidence."); RICHARD NISBETT \& LEE ROSS, HUMAN INFERENCE 167 (1981) ("Few critiques of human judgmental failings ring as true as Bacon's ... attack on people's tendency to adhere to a preconceived belief ...."); Charles G. Lord et al., Biased Assimilation and Attitude Polarization: The Effects of Prior Theories on Subsequently Considered Evidence, 37 J. PERSONALITY \& SOC. PSYCHOL. 2098, 2099 (1979) ("[I]ndividuals will dismiss and discount empirical evidence that contradicts their initial views but will derive support from evidence, of no greater probativeness, that seems consistent with their views.").

"Jonis and Mann, like other psychologists, use the term "preconscious" to describe this form of bias that operates just outside of consciousness, and explore its implications for group decisionmaking. See IRVING L. JANIS \& LEON MANN, DECISION MAKING 95-96 (1977) (describing "preconscious" emotional impulses as those of which a person may become aware if someone induces her to scrutinize her thoughts). Managerial self-deception is a partial but important theme underlying the demise of some American corporations in Farry Levinson, Why the Behemoths Fell: Psychological Roots of Corporate Failure, 49 AM. PSYCHOL. 428 (1994). 
From this, we can see how even a single manager, acting alone, would tend unconsciously to resist the significance of information calling into question the viability of a course of action-something particularly troubling given the tendency in many companies, noted in Part II, to have as a norm that information is to be passed upward to supervisory managers only if it is both significant and unusual. ${ }^{117}$ Successful companies naturally produce positive schemas: previous challenges overcome, financing obtained, and products successfully brought to market. A new product is begun in an environment where the decisionmakers agree that there is a sound basis for its development. That becomes the schema (or "script"), and potentially troubling bits of information are subject to dismissal or rationalization, without much conscious deliberation, if they can be processed consistently with the original belief. ${ }^{118}$ The tendency to ignore evidence of change in one's environment is likely to be especially strong when, as they usually do, the bits of information come sequentially in small doses rather than aggregated in some salient event.

While we can explain cognitive conservatism simply in terms of bounded rationality, it also has the motivational role of reducing stress. Revising a schema is anxiety-provoking, especially if it opens up a host of troubling possibilities. Subconsciously, busy executives do not want to be bothered with disconfirming information, and so will seek to minimize the threat. Like most everyone (except the neurotic, who do not thrive in business settings), they will tend to ignore risks that appear to have little probability of occurring. ${ }^{119}$ Again,

117 See supra notes 60-63 and accompanying text.

${ }^{118}$ A fascinating account of the influence of script-based cognitive conservatism on Ford's Pinto experience-written by a psychologist who, prior to becoming an academic, was one of Ford's recall managers-is given in Dennis A. Gioia, Pinto Fires and Personal Ethics: A Script Analysis of Missed Opportunities, $11 \mathrm{~J}$. Bus. ETHICs 379 (1992). Another illuminating discussion, concentrating on Boise Cascade's ill-fated expansion in the area of retail building supplies, is Erhard $\mathrm{K}$. Valentin, Anatomy of a Fatal Business Strategy, 31 J. MGMT. STUD. 359 (1994).

${ }^{119}$ This is a well-known phenomenon. See, e.g., Colin Camerer \& Howard Kunreuther, Decision Processes for Low Probability Risks: Policy Implications, 8J. POL'Y ANALYSIS \& MGMT. 565, 570 (1987) (examining how people make judgments about lowprobability, high-consequence risks). An interesting study of how organizations plan for low-probability events that they choose to consider-and the unrealistic way they often do so-is Lee Clarke \& Charles Perrow, Prosaic Organizational Failure, 39 AM. BEHAV. SCI. 1040 (1996). Legal rules may also account for people's failure to consider risks that appear to have little probability of occurring. See Eisenberg, supra note 3, at 232-35 (arguing that liquidated-damage provisions in contracts may be adjusted when damages are unexpectedly high); Clayton P. Gillette, Commercial Relationships and the 
the preferred course is dismissal or explanation in conformity with the existing schema; it takes a fairly vivid or salient threat to prompt revision. ${ }^{120}$ In general, then, we can predict that most managers will systematically underestimate external threats to success.

These tendencies are strengthened when managers work in teams or share decisionmaking responsibility. Because of the demands of communication and negotiation, groups can attend to even less information than individuals, leading to a tendency to simplify agendas in order to make decisions tractable. ${ }^{12 l}$ This is frequently done by focusing the group's attention only on immediate, first-level effects, putting out of mind the more complicated and unpredictablethough potentially important-second-level and systematic consequences. Ambiguous information tends to be dismissed as unmanageable: ${ }^{122}$ There is an excessively high test of materiality. In an intriguing article on ethical decisionmaking, David Messick and Max Bazerman note both the tendency of many managers to be intolerant of uncertain data-for example, the "tough-minded executive," who, in evaluating potential hiring discrimination, will accept only specific instances of demonstrable bias, not statistics and probabilities-as well as a tendency toward circumscribed information searches in reaching decisions, thereby forcing an underestimation of the impact

Selection of Default Rules for Remote Risks, 19 J. LEGAL STUD. 535, 562-74 (1990) (examining risk attitudes in commercial activities).

${ }^{120}$ See NISBETT \& ROSS, supra note 115, at 167-92 (discussing belief perseverance in the face of disconfirming evidence and the infrequent situations in which beliefs do change).

${ }^{121}$ On the organizational need to simplify, see Danny Miller, The Architecture of Simplicity, 18 ACAD. MGMT. REV. 116 (1993).

${ }_{122}$ See Craig D. Parks \& Rebecca A. Cowlin, Acceptance of Uncommon Information into Group Decisions When That Information Is or Is Not Demonstrable, 66 ORG. BEHAV. \& HUM. DECISION PROCESSES 307, 307 (1996) ("Facts that are known by only one member are treated with skepticism by others and do not factor terribly into the group's decision."); see also Peter H. Kim, When What You Know Can Hurt You: A Study of Experiential Effects on Group Discussion and Performance, 69 ORG. BEHAV. \& HUM. DECISION PROCESSES 165, 165-66 (1997) (discussing the bias of group members toward discussing common information). This is not to say that under some particular circumstances, group-decision processes cannot improve decisionmaking. See, e.g., Norbert L. Kerr et al., Bias in Judgment: Comparing Individuals and Groups, 103 PSYCHOL. REV. 687, 713 (1996) (concluding that there is no answer to the question whether groups or individuals are more biased, and noting that group size, individual judgment, magnitude and type of bias, and the group-judgment process will influence a group's susceptibility to judgment bias). Groups, for instance, are good at filtering out nonsystematic kinds of errors to which a particular member might be inclined. The point is simply that group dynamics can intensify the influence of motivations that are shared among group members. 
on secondary stakeholders and a failure to appreciate the risk that strategic forms of "cheating" will be detected. ${ }^{123}$ Here, we see how risks that might meet the lawyer's test for materiality in a disclosure environment would be given less weight, and less attention, in the primary business setting.

Groups are also motivated to preserve cohesiveness (and the efficacy of their decisionmaking norms and procedures), and this too can sometimes result in the underestimation of risk. When a member brings up some information that suggests that the group's decisionmaking has failed to consider something troubling, a threatening form of stress is introduced into the environment. Without realizing it, each member is inclined to dismiss or ignore danger signals, leading to less informed decisionmaking that more closely resembles collective rationalization than prudent choice. ${ }^{124}$ Moreover, even if a group member privately wonders whether some bit of information is troubling, the very fact that other group members do not appear to be concerned is a reason to let the matter drop, a process of social learning that has a dangerous circularity to it. ${ }^{125}$ This is especially powerful when there is a diffusion of responsibility among group members such that none feels compelled to lead and each can justify silence. ${ }^{126}$ The term given to the group-cohesion phenomenon by Irving Janis is "groupthink," and it is commonly used as an explanation for myopic corporate and political behavior. ${ }^{127}$ A group of senior

${ }^{123}$ David H. Messick \& Max H. Bazerman, Ethical Leadership and the Psychology of Decision Making, SLOAN MGMT. REV., Winter 1996, at 9, 10-11; see also Charles R. Schwenk, Cognitive Simplification in Strategic Decision-Making, 5 STRATEGIC MGMT. J. 111, 112-22 (1984) (identifying and discussing cognitive simplification processes which affect decisionmaking process).

124 See JANIS \& MANN, supra note 116, at 129 ("When [the concurrence-seeking] tendency is dominant, the members use their collective cognitive resources to develop rationalizations supporting shared illusions about the invulnerabilitiy of their organization or nation and display other symptoms of 'group-think'-a collective pattern of defensive avoidance." (citation omitted)).

${ }^{125}$ See, e.g., ROBERT P. GANDOSSY, BAD BUSINESS 224-28 (1985) (describing the process by which various accountants and investment bankers ignored signs that a company was engaged in fraud, each pointing to the fact that since the others did not act concerned, neither should they).

126 See JeFFrey PFEFFer, MANAGING WITH POWER 207-13 (1992) (examining the influence of informal social interaction and social consensus on the decisionmaking process). The effects of diffusion are explored in Albert Bandura, Social Cognitive Theory of Moral Thought and Action, in 1 HANDBOOK OF MORAL BEHAVIOR AND DEVELOPMENT 45, 84-86 (William M. Kurtines \& Jacob L. Gewirtz eds., 1991).

${ }^{127}$ See JANIS, supra note 112, at 8 (defining and analyzing the effect of groupthink on political decisions). The stress-oriented explanation for group biases is elaborated by Janis in his book with Leon Mann. See JANIS \& MANN, supra note 116, at 129-30 
managers that unconsciously deflects threatening information to preserve internal solidarity might well then disseminate inaccurate corporate publicity.

\section{Overoptimism and the Illusion of Control}

We now move more squarely into the motivational sphere. One of the most robust findings in the literature on individual decisionmaking is that of the systematic tendency of many people to overrate their own abilities, contributions, and talents. This egocentric bias readily takes the form of excessive optimism and overconfidence, coupled with an inflated sense of ability to control events and risks. ${ }^{128}$ In explaining good and bad fortune, people are asymmetric: Positive events are the product of their skill, negative ones of external circumstances. Furthermore, people filter self-referential information with the same asymmetry to bolster or maintain self-esteem. ${ }^{129}$ As with the biases discussed in the previous subsection, these are largely unconscious ones. ${ }^{130}$ While some outward expressions of optimism and confidence are deliberate forms of impression management, psychologists believe that most often the person truly accepts the excessively positive self-schema. Self-deception is necessary to sustain the illusion effectively, diminishing the anxiety produced by too much selfdoubt. ${ }^{131}$

(describing "groupthink" as a "collective pattern of avoidance"). Tests of groupthink offer considerable support for the phenomenon as a potential behavioral explanation; however, one must be cautious not to universalize it. See Philip E. Tetlock et al., Assessing Political Group Dynamics: A Test of the Groupthink Model, 63 J. PersonaliTy \& Soc. PSYCHOL. 403, 403 (1992) (explaining the validity of the groupthink model).

${ }^{123}$ See MAX H. BAZERMAN, JUDGMENT IN MANAGERIAI DECISION MAKING 37-39 (3d ed. 1994) (discussing overconfidence among managers). For instance, a sample of people who indicated near total certainty (1000-to-1 odds) that their judgments were right were in fact right only about $81 \%$ to $88 \%$ of the time. See id. at 38 .

${ }^{129}$ See, e.g., David Dunning et al., A New Look at Motivated Inference: Are Self-Serving Theories of Success a Product of Motivated Inference?, 69 J. PERSONALITY \& SOC. PSYCHOL. 58, 58-59 (1995) (suggesting that people create models of excellence "in their own image," in part, to bolster self-esteem); Anthony G. Greenwald, The Totalitarian Ego: Fabrication and Revision of Personal History, 35 AM. PSYCHOL. 603, 608 (1980) (discussing "a form of belief in personal infallibility").

${ }^{130}$ See supra note 116 and accompanying text.

131 See Jeff Greenberg et al., Why Do People Need Self-Esteem?: Converging Evidence That Self-Esteem Serves an Anxiely Buffering Function, 63 J. PERSONALITY \& SOC. PSYCHOL. 913, 913-21 (1992) (illustrating that self-esteem serves an anxiety-buffering function). There are, of course, natural limits to the extent to which these distortions are possible. See Roy F. Baumeister, The Optimal Margin of Illusion, $8 \mathrm{~J}$. Soc. \& CuINICAL PSYCHOL. 176, 176 (1989) (noting that "normal, healthy, well-adjusted people system- 
Evidence suggests that groups can increase optimistic biases, ${ }^{132}$ and, in fact, overconfidence in business organizations is predictable and frequently observed in field studies of particular firms. Optimists are prized in the hiring process. For example, one of the leading research psychologists in this area, Martin Seligman of the University of Pennsylvania, has designed hiring tests to assess high levels of optimism for numerous corporations, including Metropolitan Life's sales force. ${ }^{193}$ And, as noted in Part II, there is good reason to believe that the tournament-like competition for promotion up the executive ladder overweights optimism and its associated behavioral traits, inflating such behavior toward the top of the hierarchy. ${ }^{134}$ This is especially so in industries, like many service ones, where a sales and marketing culture dominates.

For obvious reasons, the prevalence of illusory control in many businesses can become systematic, infecting the company's overarching belief system. Numerous studies offer evidence of it. Edward Zajac and Max Bazerman, for example, contend that these cognitive biases are the primary explanation for a host of suboptimal strategic decisions of the type chronically observed in industry: overbidding for assets, plant overexpansion, and foolish entry into new lines of business. ${ }^{135}$ As much as anything, they say, systematic overcommitment derives from the inculcated and persistent belief-one that tends not to be eroded by learning and experience ${ }^{136}$-that one's own company is superior to its competitors, leading to an underestimation of the competitors' likely responses to a strategic move. ${ }^{137}$ This expla-

atically distort their views of self and world,... deriv[ing] important benefits from doing so" and suggesting that "there is an optimal margin of illusion at which people are happiest, function best, and so forth").

${ }_{132}$ See Chip Heath \& Forest J. Jourden, Illusions, Disillusions and the Buffering Effects of Groups, 69 ORG. BEHAV. \& HUM. DECISION PROCESSES 103, 104-06 (1997) (indicating that working in groups buffers participants from negative feelings that individuals often have after completing a project); Robert $\mathrm{H}$. Mnookin \& Lee Ross, Introduction to BARRIERS TO CONFLICT RESOLUTION 3, 18 (Kenneth J. Arrow et al. eds., 1995) (discussing "optimistic overconfidence" as one example of people's tendency to place unwarranted confidence in their predictions about future events).

133 See MARTIN E.P. SELIGMAN, LEARNED OPTIMISM 100-12 (1991).

134 See supra notes 66-69 and accompanying text.

135 See generally Edward J. Zajac \& Max H. Bazerman, Blind Spots in Industry and Competitor Analysis: Implications of Interfirm (Mis)perceptions for Strategic Decisions, 16 ACAD. MGMT. REV. 37 (1991).

${ }^{136}$ See supra note 111 (discussing the persistence of biases and people's failure to learn from experience).

${ }^{137}$ See Zajac \& Bazerman, supra note 135 , at 40 (" $[\mathrm{C}]$ ompetitors tend to insufficiently consider the contingent decisions of their competitive others ...."). 
nation also underlies much of the work on the so-called "winner's curse": the tendency for the winner of any auction to find later that he has overpaid. ${ }^{193}$ As a number of scholars have noted in explaining why tender offers so often turn out to be unprofitable to the acquirer, there is significant hubris in believing that the person who has placed the highest value on an asset is likely to have made the most accurate valuation. ${ }^{139}$

If overoptimism and the illusion of control come to affect a company's belief system, then the tendency to underestimate or rationalize risk in preparing publicity and disclosure will surely be exacerbated. Faced with some evidence that a product under development is failing and market share is eroding, managers in many companies will honestly believe that these are minor challenges that can readily be overcome. They will draw on inflated schemas of past successes and underrate their competitors' ability to capitalize. ${ }^{140}$

Furthermore, a "can-do" culture built on these adaptive biases will prize the dismissal of risk and reject any effort to accept and acknowledge their seriousness publicly. As we saw previously, belief systems are powerful and need nurturing. ${ }^{141}$ Moreover, disconfirming information is stress-inducing, and the need to protect the management group's cohesion will result in the dismissal or rationalization of problems if there is a plausible basis for so doing. Such belief systems may not easily tolerate forms of publicity or disclosure that are at odds with the corporate self-image.

${ }^{13 S}$ See BAZERMAN, supra note 128 , at 166-69 (discussing the "winner's curse" in competitive bidding).

${ }^{139}$ See Bernard S. Black, Bidder Overpayment in Takeovers, 41 STAN. L. REV. 597, 624 26 (1989) (discussing overpayment as the result of managers' overoptimism and ignorance); Richard Roll, The Hubris Hypothesis of Corporate Takeovers, $59 \mathrm{~J}$. Bus. 197, 197 (1986) (arguing that bidding firms infected by hubris pay too much for their targets). For an excellent survey of this phenomenon from a behavioral perspective, see Matthew L.A. Hayward \& Donald C. Hambrick, Explaining the Premiums Paid for Large Acquisitions: Evidence of CEO Hubris, 42 ADMIN. SCI. Q. 103 (1997). The finance literature increasingly points to the risk of hubris and overconfidence as well. See, e.g., David Hirshleifer et al., Security Analysis and Trading Patterns When Some Investors Receive Information Before Others, 49 J. FIN. 1665, 1686 (1994) (arguing that "because some investors receive information earlier than others, overconfidence will promote herding"); Raghuram Rajan \& Henri Servaes, Analyst Following of Initial Public Offerings, 52 J. FIN. 507, 517 (1997) (examining the effects of analyst optimism on the performance of initial public offerings).

${ }^{140}$ See Zajac \& Bazerman, supra note 135, at 40 (noting "the failure of the competitive actor to sufficiently consider the contingent decisions of the opponent $t^{n}$ ).

${ }^{141}$ See supra notes 106-08 and accompanying text. 


\section{Commitment}

Commitment is one of the foundational concepts of both individual and organizational psychology. ${ }^{142}$ Once a person voluntarily commits to an idea or course of action, there is a strong motivation to resist evidence that it was ill-chosen. Self-confidence and external image are threatened both by introducing a troubling awareness of the possibility of mistake and by raising the need to consider a reversal of one's position, which, in turn, calls into question one's reputation for consistency, a highly valued asset in our economic culture. ${ }^{143}$ Cognitive-dissonance theory predicts that once a commitment is made, attitudes and beliefs will shift to preserve consistency. ${ }^{144}$ Sales people and negotiators know well that once a person takes a few steps toward some purchase or deal, the likelihood of agreement increases. $^{145}$

The management literature strongly suggests that once executives have committed to a course of action, their subsequent survey of information is strongly biased to bolster their choice-especially when their choice is public, and they can be held accountable for their de-

${ }^{142}$ See D. Ramona Bobocel \& John P. Meyer, Escalating Commitment to a Failing Course of Action: Separating the Roles of Choice and Justification, 79 J. APPLIED SOC. PSYCHOL. 360, 363 (1994) (presenting research findings that private and public justifications influence a decisionmaker's escalating commitment); Barry M. Staw, The Escalation of Commitment to a Course of Action, 6 ACAD. MGMT. REv. 577, 584 (1981) (discussing research on the escalation of commitment); Glen Whyte et al., When Success Breeds Failure: The Role of Self-Efficacy in Escalating Commitment to a Losing Course of Action, $18 \mathrm{~J}$. ORG. BEHAV. 415, 416-18 (1997) (tying commitment to self-efficacy and overconfidence). Of course, one cannot be sure that commitment is necessarily a bias; a rational actor might remain committed to a course of action if she fears that discovery of the mistake will lead to termination. See Chandra Kanodia et al., Escalation Errors and the Sunk Cost Effect: An Explanation Based on Reputation and Information Asymmetries, 27 J. ACCT. RES. 59, 60 (1989) (suggesting that managers may escalate their commitment to protect their reputations).

${ }^{113}$ See Staw, supra note 142 , at 580-81 (emphasizing the virtue of appearing consistent).

${ }^{144}$ See Elliot ARonson, The Social ANimal 178-79 (7th ed. 1995) (noting that cognitive dissonance, namely, "a state of tension that occurs whenever an individual simultaneously holds two cognitions (ideas, attitudes, beliefs, opinions) that are psychologically inconsistent," is reduced "[b]y changing one or both cognitions in such a way as to render them more compatible (more consonant) with each other, or by adding more cognitions that help bridge the gap between the original cognitions").

${ }^{145}$ See RoberT B. Cialdini, INFLUENCE 13, 15 (3d ed. 1993) (noting the common sales technique of selling an expensive item to a customer first to induce the customer to buy other less expensive items as well, and the common practice of car dealers of adding individual options after the price of the car has been negotiated to reduce a customer's resistance). 
cisions. ${ }^{146}$ Bolstering evidence is actively sought, while disconfirming information is subconsciously resisted. Although we can see a possible rational basis here grounded in the last-period problem, the weight of authority supports the position that managers come to believe in the efficacy of projects for which they are responsible, objective evidence often notwithstanding. Hence, the phenomenon of "throwing good money after bad." Various scholars have identified the commitment bias as a primary cause of the chronic overcapacity often observed in industry. ${ }^{147}$

\section{Self-Serving Beliefs}

Both the optimistic and commitment biases raise a troubling concern. Beliefs that lead to throwing good money after bad in an effort to avoid acknowledging a mistake to one's self or to the public seem to be fairly selfish forms of inference. ${ }^{148}$ This presents the possibility that certain forms of managerial beliefs may not necessarily be molded in the company's best interests-though that may be the

${ }^{116}$ Postdecisional bolstering takes place in settings of accountability, even though accountability otherwise tends to improve decision quality. See, e.g., Philip E. Tetlock et al., Social and Cognitive Strategies for Coping with Accountability: Conformity, Complexity and Bolstering, 57 J. PERSONALITY \& SOC. PSYCHOL. 632, 638 (1989) (noting that subjects who committed themselves to positions engaged in less self-criticism and were more concerned with self-justification). I have suggested that this commitment bias may prevent lawyers from fully appreciating the risk of client wrongdoing, making them less than fully competent gatekeepers. See Donald C. Langevoort, Where Were the Lauyers?: A Behavioral Inquiry into Lauyer Responsibility for Clients' Fraud, 46 VAND. L. REV. 75, 111 (1993) ("[T]here are reasons ... to doubt that lawyers will be very good gatekeepers once they have committed to representation and built a positive schema regarding the client and the situation.").

${ }^{147}$ See Zajac \& Bazerman, supra note 135, at 45, 47 (noting that firms may irrationally escalate commitment to expand capacity). On overcapacity generally, see MiCHAEl E. PORTER, COMPETITIVE STRATEGY 328 (1980). An interesting account of the escalation of commitment to a course of action as applied to an example of managerial wrongdoing-the dilution of apple juice by Beech-Nut executives-can be found in PHILIP G. ZiMBARdo \& MichaEL R. LIEPPE, THE PSYCHOLOGY OF ATTITUdE CHANGE AND SOCIAL INFLUENCE 120-21 (1991). For another example, dealing with Long Island Lighting Company's decision to build the Shoreham Nuclear Power Plant, see Jerry Ross \& Barry M. Staw, Organizational Escalation and Exit: Lessons from the Shoreham Nuclear Power Plant, 36 ACAD. MGMT. J. 701 (1993).

${ }^{14}$ Not so, of course, if this commitment bias simply reflects cognitive conservatism and inflated self-efficacy, especially if derived from the organization's own biases. The point here is that disentangling self-serving and business-oriented biases may not be so easy. See Andrew D. Brown, Narcissism, Identity and Legitimacy, 22 ACAD. MGMr. REV. 643,648 (1997) (noting both the functional and dysfunctional elements of organizational egocentrism). 
outward impression-but rather they reflect the self-serving biases of its senior managers.

The notion of self-serving inference is another fundamental construct in social cognition. ${ }^{149}$ When there is enough ambiguity to permit it, people naturally "see what they want to see." 150 And what they want to see is something that is in their self-interest, not a threat to either their self-esteem or career prospects. That threat is stressful, and, to a small group, upsets cohesion. ${ }^{151}$ It is, therefore, resisted. This is not to say that management control groups live in settings of blissful ignorance. Much information is too unambiguous to deflect: Corporations do have regular feedback in the form of sales data, cash flow, and the like. Self-serving inference is an anxiety buffer, not an anxiety eliminator. Management groups may subconsciously perceive information in a way, if at all possible, that permits them to maintain consistency with their self-image of efficacy and control, thereby justifying (to themselves and others) preservation of their positions and status. They will be adept at the self-deception that leads them to persuasively articulate the corporate interest in full consistency with their personal goals.

149 See, e.g., Dennis A. Gioia, Self-Serving Bias as a Self-Sensemaking Strategy: Explicit us. Tacit Impression Management, in IMPRESSION MANAGEMENT IN THE ORGANIZATION 219, 230-33 (Robert A. Giacalone \& Paul Rosenfeld eds., 1989) (concluding that the objective of dealing with self-serving bias should be to manage it, not squelch it); George Loewenstein, Behavioral Decision Theory and Business Ethics: Skewed Trade-offs Between Self and Other, in CODES OF Conduct 214, 221 (David M. Messick \& Ann E. Tenbreusel eds., 1996) (noting that "[o]ne of the most important nonobjective influences on information processing is self-interest"). The most common manifestation is the tendency to construe what is right or fair in a self-serving direction. See George Loewenstein et al., Self-Serving Assessments of Faimess and Pretrial Bargaining, 22 J. LEGAL STUD. 135,139 (1993) (" $[P]$ redictions of the value of the claim and judgments of what settlement would be fair are both biased in a self-serving manner. Moreover, the magnitude of the bias is a strong predictor of nonsettlement.").

${ }^{150}$ See ThOMAS GILOVICH, HOW WE KNOW WHAT ISN'T So 75-87, 76 (1991) (discussing the "tendency for people to believe ... what they want to believe"). This is a classic form of motivated reasoning. See, e.g., Peter H. Ditto \& David F. Lopez, Motivated Skepticism: Use of Differential Decision Criteria for Preferred and Nonpreferred Conclusions, 63 J. PERSONALITY \& SOC. PSYCHOL. 568, 568 (1992) (examining "the notion that people are less skeptical consumers of desirable than undesirable information"); J. Edward Russo et al., The Distortion of Information During Decisions, 66 ORG. BEHAV. \& HUM. DECISION PROCESSES 102, 102 (1996) ("People seek information that confirms their choice and depreciate encountered information that opposes it.").

${ }^{151}$ We can thus include "in-group" biases within this framework. For a seminal effort to integrate in-group bias theory and corporate-law principles, see James D. Cox \& Harry L. Munsinger, Bias in the Boardroom: Psychological Foundations and Legal Implications of Corporate Cohesion, 48 LAW \& CONTEMP. PROBS. 83 (1985). 
Thus, we can see an optimistic culture as two-headed. On the one hand, it may be very useful to the firm as a motivator. On the other hand, optimism has a dark side, justifying the preservation of the status quo, and hence can also serve as an entrenchment mechanism. ${ }^{152}$ If the future is rosy, senior managers deserve not only to keep their jobs, but also to receive additional perquisites. This suggests that highly optimistic forms of belief may well strengthen in the face of increasingly disconfirming information as fed by the strong personal needs of the senior managers. In all likelihood, one way that we can measure the self-serving tendencies of top management is to examine how well they diffuse within the firm. Natural optimism should find a willing audience; more strained versions will be greeted with increasing levels of skepticism among mid-level managers-who are just as likely to engage in self-serving construal, although with different conclusions. ${ }^{153}$

The notion that self-serving inferences are pervasive and hard to disentangle from business justifications indicates an interesting connection between social psychology and conventional economics. Though a clear violation of the standard rationality assumption, this form of inference offers a reason to expect people to behave the way economists predict-in the pursuit of self-interest-even though they deny in good faith that they are acting in anything but a fair and rea-

${ }^{132}$ This is emphasized in Brown, supra note 148 , at $651-60$ (noting that denial, rationalization, self-aggrandizement, and attributional egotism are ego-defensive behaviors that may lead to ultimate failure); see also Jennifer A. Chatman et al., The Managed Thought: The Role of Self-Justification and Impression Management in Organizational Settings, in THE THINKING ORGANIZATION, supra note 20, at 191, 209-10 (noting that organizations put substantial effort into rationalizing actions and events); Hayward \& Hambrick, supra note 139, at 107 (noting that success reinforces a CEO's stature but often leads to self-serving attributions rather than self-critical ones). In turn, this sense of entitlement to the status quo (or aspirations built on it) may trigger a host of cognitions and behaviors designed to cling to it. For instance, one of the standard biases identified in the literature (under the heading of prospect theory) suggests that people will take greater risks in order to avoid a loss than to seek a gain. See, e.g., Amos Tversky \& Daniel Kahneman, Rational Choice and the Framing of Decisions, $59 \mathrm{~J}$. Bus. S251, S258 (1986) ("A significant property of the value function, called loss aversion, is that the response to losses is more extreme than the response to gains."). Accordingly, self-serving managerial biases may ultimately lead to risky decisions to preserve the status quo, all hidden from consciousness in the name of "business judgment."

${ }^{153}$ This leads to the natural point that there is not likely to be a single corporate culture, but many subcultures with greater or lesser linkages. Because corporate disclosure tends to be in the hands of a small group at the top of the organization, it would not be surprising to find self-serving interpretation a significant influence on the content of filings and official publicity. 
sonable fashion. ${ }^{154}$ As ethicists increasingly recognize, antisocial behavior in business settings may be less the product of base moral corruption than of the ability of normal people in stressful environments to distort and rationalize. ${ }^{155}$ In this sense, self-serving inferences may be particularly useful in understanding the nature and persistence of agency costs and the moral hazards in organizational economics.

\section{Bundling the Stories}

Although each of the foregoing behavioral biases is interesting by itself, the practical implications follow from their interplay. Burgelman's story of Intel recounted at the beginning of this Article ${ }^{156}$ is essentially one of senior management's inertial resistance to the disconfirmation of a highly success-oriented schema, albeit in a setting where learning ultimately did occur. As such, accounts of why companies make misleading disclosures should seek to integrate the various biases. And from these biases, it is easy to tell a generic story behind the kind of fraud allegation involving Apple Computer, ${ }^{157}$ TimeWarner, ${ }^{158}$ Polaroid, ${ }^{159}$ and many other defendants in the "false optimism" cases. In most of these cases, a highly successful organization undertook a course of action with respect to some product or financial strategy and was sued for not disclosing some bits of adverse in-

154 For this reason, the kinds of selfish "last period" behavior that Arlen and Carney describe, see supra notes 40-44, 46 and accompanying text (discussing Arlen and Carney's theory), is likely to be subject to self-deception. The managers engaged in such behavior will not recognize it as such but will develop business-oriented rationalizations.

155 See Russel Hardin, The Psychology of Business Ethics, in CODES OF CONDUCT, supra note 149, at 342, 359 ("At first cut, it is plausible that there is far more failure of rationality than morality in organizations ...."); Barry A. Stein \& Rosabeth M. Kanter, Why Good People Do Bad Things: A Retrospective on the Hubble Fiasco, ACAD. MGMT. EXECUTIVE, Nov. 1993, at 58, 62 (using the Hubble Telescope project as a paradigm for "normal accidents" in organizations and concluding that "the Hubble project failed because of faulty mental images; images reified in the project organization, in the relationships it fostered and thus, in the very process of operationalizing the total concept of a space telescope").

${ }^{156}$ See Burgelman, supra note 8 , and accompanying text.

${ }^{157}$ See In re Apple Computer Sec. Litig, 886 F.2d 1109, 1119 (9th Cir. 1989) (finding triable issue as to whether optimistic statements were misleading).

${ }^{158}$ See In re Time Warner Sec. Litig., 9 F.3d 259, 261 (2d Cir. 1993) (deciding the question of "whether a corporation has a duty to update somewhat optimistic predictions ... when it appears that [they] will not be realized").

${ }^{159}$ Backman v. Polaroid Corp., 910 F.2d 10, 16 (1st Cir. 1990) (en banc) (noting duty to correct misleading statement when issuer learns that the statement is misleading). 
formation later found in the company's files. This is precisely the kind of situation where each of the biases can readily operate: The firm was successful, and no doubt had a good deal of aggregate selfesteem; the adverse bits of information were slow in coming and inconsistent with well-established schemas; and there was a heavy commitment to the success of the projects. It is perfectly plausible that, especially in the first small steps toward committing to the project-a point of very high ambiguity-individual managers were particularly optimistic. In the early stages of the project, this optimistic schema was resistant to the first (still ambiguous) bits of potentially disconfirming information. By the time their seriousness started to become clearer, there was a high degree of commitment to strengthen the prevailing beliefs, not to mention strong political reasons for preserving the status quo. Moreover, by that time the managers were committed to their publicly expressed optimism, from which they could not easily step away, even as the signs of trouble became palpable. Only at that late stage was there a truly deliberate form of dissembling. The temporal interplay between initial overoptimism (leading one to underestimate the risk of later dilemmas at the beginning of a course of action) and the commitment bias (leading toward continuation once those first steps are completed) -an optimism-commitment "whipsaw"-is an especially interesting explanation for why otherwise good people often find themselves responsible for bad behavior. ${ }^{160}$

We can also draw some important connections between the organizational-cognition accounts discussed earlier in this section ${ }^{161}$ and the informational account offered in Part II. ${ }^{162}$ Information flow is likely to be distorted not only (or even so much) by conscious distortion, but also by biased interpretation. ${ }^{163}$ To the extent that managers exhibit both cognitive conservatism and an optimistic-or selfserving-frame of reference, fewer danger signs will qualify for reporting treatment as unusual, and those that do will tend to have a positive spin. This more subtle winnowing and revisionism is re-

${ }^{160}$ See John M. Darley, How Organizations Socialize Individuals into Evildoing, in CODES OF CONDUCT, supra note 149, at 13, 16-25 (discussing fragmentation of information and commitment to courses of action).

${ }^{161}$ See supra Part III.A.1-4.

162 See supra Part II.A.

${ }^{163}$ See ARROW, supra note 60, at 57 (noting the possibility of bias in information flow). For this reason, I would revise the analysis in Part II to reduce the emphasis on deliberate information distortion and put in its place the assumption that a good bit of reporting is in good faith, but nonetheless misleading. 
peated at each relay point, with predictable effects on the final message. ${ }^{164}$

\section{B. Can Biases Persist?}

The tension between the orthodox economic and the alternative social-science accounts of organizational behavior is most clearly posed in a single question: If business firms exist in competitive environments, will not market forces weed out those firms that act in a less-than-rational, and hence inefficient, fashion ${ }^{165}$ In other words, should we not expect those firms with unrealistic belief systems that do not learn from their errors to disappear, leaving only those that have successfully countered the problem of cognitive bias? This Darwinian question is particularly apt because the problems of managerial myopia and excessive optimism are hardly unknown within the business community; scores of books, consultants, and educational programs exist to alert managers to them and point to ways of avoiding them. ${ }^{166}$ Many companies have adopted structures designed specifically to avoid biases in the decisionmaking process. ${ }^{167}$

Answering this question is the most important item on the behavioral-research agenda. Before turning to a set of responses, however, it should be emphasized that even if competitive forces do gradually weed out firms that generate unrealistic belief systems, the process of decisionmaking remains descriptively interesting. Our immediate effort is to explain why companies might deceive the stock markets, and to see what this says about securities law. Unless we make the strong

${ }^{164}$ Argyris and Schön, for example, contend in a review of Burgelman's account of Intel's cognitive blindness that senior management's myopia can be only a partial explanation for its inability to hold its competitive lead. Their additional explanation is that "defensive" breakdowns in communication prevented senior management from becoming fully aware of the possibility of the loss of position. See ARGYRIS \& SCHŌN, supra note 8 , at $218-21$.

${ }^{165}$ See supra note 111 (discussing the general debate on this subject between economists and psychologists). For a legal perspective, see Roberta Romano, A Comment on Information Overload, Cognitive Illusions and Their Implications for Public Policy, 59 S. CAL. L. REV. 313 (1986).

${ }^{166}$ Some examples of books or articles that specifically address organizational "debiasing" are BAZERMAN, supra note 128, at 196-99; JANIS \& MANN, supra note 116, at 367-404; JAMES G. MARCH, A PRIMER ON DECISION MAKING (1994); and Mary Reis Louis \& Robert I. Sutton, Switching Cognitive Gears: From Habits of Mind to Active Thinking, 44 HUM. REL. 55 (1991).

${ }^{167}$ Some banks, for example, keep their work-out teams separate from their lending groups to avoid the commitment bias. See Staw, supra note 142, at 585 (discussing a comparative study examining two banks coping with delinquent loans). 
and unrealistic assumption that overly optimistic or otherwise biased organizations never even enter markets in which more rational competitors exist, the category of companies that might be charged with fraud will always include some that are at risk of being eliminated because of their bias, but have not yet been. This "temporary entrant" category-with some hyperbole, the corporate equivalent of Barnum's new sucker born every minute ${ }^{168}$ - would still be of significance to understanding the nature and sources of corporate deception. Indeed, given that corporate failure of some sort or another is a common precursor to class-action litigation, it may be a particularly important category. We need not rest here, however, for there are other survivability accounts that deserve careful consideration, each interesting by itself but, like the biases themselves, probably most powerful in combination.

\section{Contingency, Imperfect Competition, and the Limits of Learning from Experience}

The first possible answer to the question of why competition does not assure organizational rationality is an obvious one: There is no such thing as a fixed or immutable organizational belief system. Although corporate cultures do allow for a certain degree of stability even when there is substantial turnover of key personnel, they can and do shift over time. The most obvious example of this is what March and his colleagues refer to as a competency trap. ${ }^{169}$ A firm may

${ }^{163}$ Lynn Stout has made a similar point regarding investor behavior. See Lynn A. Stout, Are Stock Markets Costly Casinos? Disagreement, Market Failure, and Securities Regulation, 81 VA. L. REV. 611, 639-40 (1995) (noting that each new generation of investors has a subset of investors who are overly optimistic of their abilities to trade).

169 See Barbara Levitt \& James G. March, Organizational Learming, 14 ANN. REV. Soc. 319,322 (1988) (" $[\mathrm{A}]$ competency trap can occur when favorable performance within an inferior procedure leads an organization to accumulate more experience with it, thus keeping experience with a superior procedure inadequate to make it rewarding to use."); see also Danny Miller, What Happens After Success?: The Perils of Excellence, $31 \mathrm{~J}$. MGMT. STUD. 325, 326 (1994) ("[M]anagers tend to attribute success to some pet policy, strategy or process, which as a result, becomes resistant to change."). Levitt and March also stress, as do many other theorists, the difficulties associated with learning from experience in any situation where feedback is not both unambiguous and prompt, something rarely observed in business settings. See Levitt \& March, supra, at 320 (stating that routines "adapt to experience incrementally in response to feedback"); see also, e.g., Berndt Behmer, In One Word: Not from Experience, in JUDGMENT AND DECISION MAKING 705, 719 (Hal R. Arkes \& Kenneth R. Hammond eds., 1986) (concluding that "experience often gives us very little information to learn from"); Ed Bukszar \& Terry Connolly, Hindsight Bias and Strategic Choice: Some Problems in Leaming from Experience, 31 ACAD. MGMT. J. 628, 630 (1988) (noting the presence of hindsight 
act with savvy in the early stages of its development and achieve a fair level of market success. At that point, it establishes a reputation and perhaps a protectable market niche (through intellectual-property protection or proprietary internal knowledge) that give it a natural advantage over its competition. As the firm ages, this advantage may generate free cash flow that provides an additional buffer from marketplace forces. ${ }^{170}$

Even orthodox economists recognize that at this point, the power of competitive forces can diminish and the firm will turn inward in its behavior. ${ }^{171}$ Under the standard account, that facilitates managerial entrenchment and selfish behavior by incumbent executives (to which we can add, based on the self-deception discussion in the previous section, the possibility of self-serving inference perceived by the incumbent managers as if it were good business judgment). ${ }^{172}$ With product-market forces blunted, labor-market forces become less pressing, especially if the managers have invested much human capital in the particular firm. And, as is increasingly well recognized, the third principal kind of market force-capital-marketplace influencecan be marginal, at least until a crisis. ${ }^{173}$ Eventually, of course, the

bias in strategic decisionmaking); Colin F. Camerer, Comment on Noll and Krier: "Some Implications of Cognitive Psychology for Risk Regulation", 19 J. LEGAL STUD. 791, 794 (1990) (" $[E]$ valuation must be careful, frequent, and quick ... to learn from results."); supra note 111 .

${ }^{170}$ Cf. Michael C. Jensen, Agency Costs of Free Cash Flow, Corporate Finance and Takeovers, 76 AM. ECON. REV., May 1986, at 323, 323 ('Payouts to shareholders reduce the resources under managers' control, thereby reducing managers' power, and making it more likely they will incur the monitoring of the capital markets which occur when the firm must obtain new capital. Financing projects internally avoids this monitoring and the possibility the funds will be unavailable or available only at high explicit prices." (citation omitted)).

${ }^{171}$ Agency costs will vary depending on the competitive environment, which may be strong or weak. See, e.g., Michael C. Jensen, The Modern Industrial Revolution, Exit, and the Failure of Internal Control Systems, 48 J. FiN. 831, 870 (1993) ("[N]o longer can we assume managers automatically act to maximize firm value."). For a critical review from a legal perspective, see Manuel A. Utset, Towards a Bargaining Theory of the Firm, 80 CORNELL L. REV. 540, 554-56 (1995).

${ }_{172}$ See supra notes $148-64$ and accompanying text.

${ }^{173}$ The firm with minimal needs for external capital has little to worry about in terms of access. The likelihood that capital providers (for example, shareholders) will use their legal rights to demand replacement of existing management, though a growing possibility, is still the exception rather than the rule. See, e.g., Bernard S. Black, Agents Watching Agents: The Promise of Institutional Investor Voice, 39 UCLA L. REV. 811, 819 (1992) (noting that institutional investors are no longer entirely passive, but that proxy fights are still rare). Nor is it entirely clear that monitoring shareholders necessarily have a superior (or unbiased) perspective. See, e.g., D. Gordon Smith, Corporate 
firm that is too inward looking may fail as technology evolves and competitors are able to alter the competitive environment. The point, however, is that because of variations in the intensity of competition, we cannot assume that firms with bias-filled cultures will necessarily die quickly. Their biases may persist for unusually long periods of time. The result, for our purposes, is an enlargement of the category of companies that at any given time might be susceptible to the kinds of disclosure distortion that come from cognitive bias. Indeed, there is a strong strand in the "organizational ecology" literature that suggests that eventually nearly all successful firms are destined for failure as their perceptions and routines ill-prepare them for changes in technologies and market conditions. ${ }^{174}$

Quite separately, we should also take note of the difficulties associated with organizational learning and rational choice. Once a firm has exploited some technology and established itself in its market, it becomes increasingly difficult to discern what the best strategic option is. And when some choice is made, it is difficult to tell whether it was successful or not. Signals from the environment are highly ambiguous and often delayed. Nearly all failures can be ascribed, if observers are so inclined, to intervening and unforeseen situational factors rather than flaws in the decision. ${ }^{175}$ Such environments frustrate organizational learning and rational decisionmaking. In this kind of setting, rational choice readily gives way to superstitious learning, and decisions and processes that are more symbolic than real, ${ }^{176}$ not because the company is not motivated to act rationally, but rather be-

Governance and Managerial Incompetence: Lessons from Kmart, 74 N.C. L. REV. 1037, 1104 10 (1996) (doubting whether shareholder activism adds value to corporations).

${ }^{174}$ See Michael T. Hannan \& John Freeman, Structural Inertia and Organizational Change, 49 AM. SOC. REV. 149, 149 (1984) (arguing "that selection processes tend to favor organizations whose structures are difficult to change"). More recently, there has been greater attention to the possibility of organizational adaptation to new environments, although the substantial likelihood that success (ultimately) breeds failure is still recognized. See, e.g., Terry L. Amburgey \& Hayagreeva Rao, Organizational Ecology: Past, Present, and Future Directions, 39 ACAD. MGMT. REv. 1265, 1275 (1996) (questioning whether established firms become inert and unable to respond to market changes); John M. Usher \& Martin G. Evans, Life and Death Along Gasoline Alley: Darwinian and Lamarckian Processes in a Differentiating Population, 39 ACAD. MGMT. REV. 1428, 1458-62 (1996) (concluding that market change occurs both due to organizational adaptation and by outright replacement of one firm by another).

${ }^{175}$ In business settings, there is often confusion over whether a decision was poor or simply implemented badly by others. In this sense, the potential fault of others, as well as simply bad luck, can be confounding.

${ }^{176}$ See supra note 169. 
cause environmental signals leave a void soon filled in the pursuit of other, more inward-looking needs. ${ }^{177}$

\section{Adaptive Biases}

The second set of explanations for why biases might persist is different and potentially more profound. Put simply, there is reason to suspect that firms that inculcate certain types of belief systems may in many settings be competitively superior to those that are more doggedly "realistic." Though counterintuitive, this possibility finds a great deal of support in the social-psychology research relating to individual and group behavior.

As noted, there are essentially two classes of bias. One is the kind of bias arising naturally from bounded rationality and constraints on cognitive-processing ability. ${ }^{178}$ At the level of the firm, it is quite possible that stable perceptions and routines are necessary to allow it to focus on an objective and exploit it fully-even if the resulting tunnel vision eventually poses significant risks in times of external change. ${ }^{179}$ This is the virtue of organizational cognitive conservatism. It can be adaptive in two senses: First, it simplifies thinking by allowing the firm to dismiss large amounts of information; second, it is often accurate insofar as stability is more common than change. ${ }^{180}$ In an am-

${ }^{177}$ Here again we should note the interplay with the information-flow analysis: Learning is difficult to the extent that communication barriers (structural or cultural) prevent senior executives from gaining a realistic picture of any given situation. See, e.g., ARGYRIS \& SCHŌN, supra note 8, at 211 (stressing "the 'inertial' lag of formal corporate strategy in relation to shifting conditions in the competitive environment"). In addition to all this, we should note one other element of contingency: Over time, a firm's expectations will change, triggering other forms of bias that are related to the perception of the status quo. See, e.g., James G. March \& Zur Shapira, Variable Risk Preferences and the Focus of Attention, 99 PSYCHOL. REV. 172, 177 (1992) (discussing the "rate of aspiration adjustment" and "focus-of-attention" effects on organization).

${ }^{178}$ See supra note 113 (discussing purely cognitive biases).

${ }^{179}$ In Kenneth Arrow's words, "the very pursuit of efficiency may lead to rigidity and unresponsiveness to further change." ARROW, supra note 60, at 49 . For a good expression of this in the managerial literature, see DANNY MILLER, THE ICARUS PARADOX (1990), and Miller, supra note 169, at 330 . This is also a common theme in the industrial-evolution literature. See, e.g., Michael T. Hannan \& Glenn R. Carroll, An Introduction to Organizational Ecology, in ORGANIZATIONS IN INDUSTRY 17, $23-25$ (Glenn R. Carroll \& Michael T. Hannan eds., 1995) (explaining the challenges of structural inertia in established firms); Rebecca M. Henderson \& $\mathrm{Kim}$ B. Clark, Architectural Innovation: The Reconfiguration of Existing Product Technologies and the Failure of Established Firms, 35 ADMIN. SCI. Q. 9, 16-19 (1990) (discussing the problems that market innovations pose to well-established organizations).

${ }^{180}$ See Hal R. Arkes, Costs and Benefits of Judgment Errors: Implications for Debiasing, 110 PSYCHOL. BULL. 486, 487-89 (1991) (describing benefits of biases in terms of sim- 
biguous environment, too much willingness to shift directions and consider new possibilities makes reciprocal commitment difficult. Conversely, in a stable atmosphere, individual managers and employees, as well as such external constituencies as customers and suppliers, can rely on the firm to stick to a set of routines, and so are more willing to "invest" in it for the intermediate-term future. ${ }^{181}$ In sum, one adaptive quality of narrow organizational perception is to focus the firm's resources and attention on what it has for the time found that it can do well ${ }^{182}$ and avoid the informational paralysis that often comes from seeing and thus dwelling on too many risks or opportunities.

The other kind of bias is the motivated one, ${ }^{183}$ and here we see a more fascinating possibility. Much research on individual cognition indicates that the most successful person, on average, tends not to be the realist, but rather the optimist. ${ }^{184}$ High levels of self-esteem and self-efficacy are associated with aggressiveness, perseverance, and optimal risk-taking. ${ }^{185}$ These biases may be particularly adaptive in busi-

plified management of large amounts of data); Miller, supra note 121, at 118 (describing benefits of simplified focus in organizations).

${ }^{181}$ See Walter W. Powell, Expanding the Scope of Institutional Analysis, in THE NEW INSTITUTIONALISM, supra note 6, at 183, 194 ("[E] stablished conceptions of the "way things are done' can be very beneficial; members of an organizational field can use these stable expectations as a guide to action and a way to predict the behavior of others.").

${ }^{182}$ See Richard R. Nelson, Recent Evolutionary Theorizing About Economic Change, $33 \mathrm{~J}$. ECON. LITERATURE 48, 79 (1995) ("[T] he set of things a firm can do well at any given time is quite limited, and ... while firms certainly can learn to do new things, these learning capabilities are also limited.").

${ }^{183}$ See supra note 113 (discussing motivational biases).

${ }^{184}$ See FISKE \& TAYLOR, supra note 115, at 543-50 (discussing self-fulfilling prophecies); SELIGMAN, supra note 133, at 112 ("[T]he successful corporation has its optimists, dreamers, salesmen, and creators."); Pamela C. Regan et al., Unrealistic Optimism: Self-Enhancement or Person Positivity?, 21 PERSONALITY \& SOC. PSYCHOL. BULL. 1073, 1079-80 (1995) (finding that unrealistic optimism resulted in a greater chance of experiencing positive, future life outcomes); Shelley E. Taylor \& Peter M. Gollwitzer, Effects of Mindset on Positive Illusions, 69 J. PERsonalmy \& SOC. PSYCHOL. 213, 22425 (1995) (demonstrating that people tend to use positive thinking when implementing goals); see also Albert Bandura, Human Agency in Social Cognitive Theory, 44 AM. PSYCHOL. 1175, 1177 (1989) ("The successful . . f fake an optimistic view of their personal efficiency to exercise influence over events that affect their lives."). From a legal perspective, see Donald C. Langevoort, Ego, Human Behavior, and Law, 81 VA. L. REV. 853, 855-60 (1995) (discussing the cognitive mechanisms that promote self-esteem).

${ }^{185}$ The efficacy of positive illusions is not uncontroversial. See Heath \& Jourden, supra note 132, at 113 (finding that positive illusions make people overly sensitive to environmental feedback). It may be affected by matters of timing (for example, a lull in the illusion immediately after a task). See Thomas Gilovich et al., Effect of Temporal Perspective on Subjective Confidence, 64 J. PERSONALITY \& SOC. PSYCHOL. 552, 555 (1993) 
ness settings, where decisiveness and aggressiveness are considered indicators of a successful manager. ${ }^{186}$ Certainly, overconfidence at times leads to disaster and severe career failure. Those who fail too visibly are often weeded out. However, there. is little evidence that successful managers learn humility very well. ${ }^{187}$ Instead, they recharacterize their minor failures in self-serving terms. They take the apparent absence of major failures, maybe from luck as much as anything else, as proof of superior skill. High levels of optimism and confidence are not only good internal motivators, but they also influence others; exhibitions of confidence and optimism make people more persuasive and influential. ${ }^{188}$

There is no reason to believe that the same would not be true for organizational cultures generally. ${ }^{189}$ In the same vein as David Kreps's

(discussing the potential impact of accountability for assessments immediately following the task being assessed). From a research perspective, it is hard to determine whether such illusions are the cause of positive behavior, or whether initial success leads to high levels of optimism and control, thereby becoming a self-fulfilling prophecy. For a well-known social cognitionist's expression of doubt as to the value of high self-esteem (without doubting its power to affect cognition among large numbers of people), see ROBYN M. DAWES, HOUSE OF CARDS 277-82 (1994).

${ }^{186}$ See WEICK, supra note 10 , at 60 (noting the powerful adaptive effects of bold action); James G. March \& Zur Shapira, Managerial Perspectives on Risk and Risk Taking, 33 MGMT. SCI. 1404, 1414 (1987) ("[M]anagerial ideology also portrays a good manager as being a risk taker."); Leslie E. Palich \& D. Ray Bagby, Using Cognitive Theory to Explain Entrepreneurial Risk-Taking: Challenging Conventional Wisdom, $10 \mathrm{~J}$. BUS. VeNTURING 425, 434 (1995) ("When an entrepreneur pursues an activity that would be ignored or neglected by a nonentrepreneur, it may be due to the entrepreneur's perception of a positive outcome rather than to differences in predisposition to risk."); see also Kathleen M. Sutcliffe, What Executives Notice: Accurate Perceptions in Top Management Teams, 37 ACAD. MGMT. J. 1360, 1373-74 (1994) (describing the importance of accurate managerial perception of environmental characteristics so that the organizations can tailor their strategies and structures to the environment's conditions).

187 See March \& Shapira, supra note 186, at 1414 (noting that because managers believe that they can change the odds, they are more prone to accept risks than they might otherwise be).

${ }_{183}$ See Margaret T. Lee \& Richard Ofshe, The Impact of Behavioral Style and Status Characteristics on Social Influence: A Test of Two Competing Theories, 44 SOC. PSYCHOL. Q. 73, 80 (1981) (discussing how variations in demeanor significantly affect observers' decisions); $c f$. Bernard E. Whitley, Jr. \& Martin S. Greenberg, The Role of Eyewitness Confidence in Juror Perceptions of Credibility, $16 \mathrm{~J}$. APPLIED SOC. PSYCHOL. 387, 403 (1986) (finding that self-confidence leads to more credible testimony). Sociobiologists suggest that self-deception is so pervasive and adaptive precisely because it leads to an improved ability to influence (and deceive) others, something seen as a key survival trait. See ROBERT TRIVERS, SOCIAL EVOLUTION 415-20 (1985) (discussing the logic of selfdeception).

${ }^{189}$ There is support for the view that the role of positive illusions is enhanced in group settings; groups may accentuate positive feedback and offer forms of rationalization to avoid the negative. See Heath \& Jourden, supra note 132, at 114 (discussing 
hypothesis that a culture that emphasizes trust can allow the organization to signal more effectively the credibility of its commitments, ${ }^{190}$ we observe that an optimistic culture can have a number of adaptive virtues. It is an ideal motivator, creating the expectation of future growth and profitability that leads individuals to invest their human capital in the firm more willingly and to defer present consumption in favor of future rewards. Firms with "can-do" cultures will thereby generate higher levels of internal effort and, by projecting selfconfidence, be more successful in attracting external resources. ${ }^{191}$ Conversely, an optimistic culture can blind managers to the kind of anxiety about the future that might otherwise trigger both the sort of self-serving inference and the selfish "last period" kind of behavior that might operate to a firm's detriment. ${ }^{192}$ Faced with risk or trouble, agents will more likely persist in normal, functional activity than act self-protectively if the firm has successfully inculcated a belief system that rests on images of efficacy and control.

Of particular interest here is the relationship between optimism and trust. In recent years, scholars have come to recognize that the pervasiveness of trust within an organization is positively correlated with efficiency and productivity. In turn, optimism should correlate with trust. ${ }^{193}$ In any joint enterprise, the potential for opportunistic

the buffering effect of groups); see also Yechiel Klar et al., Nonunique Invulnerability: Singular Versus Distributional Probabilities and Unrealistic Optimism in Comparative Risk Judgments, 67 ORG. BEHAV. \& HUM. DECISION PROCESSES 229, 241 (1996) (extending unrealistic optimism to judgments about group peers). For an expression of the view that certain kinds of biases (including optimistic ones) are more often found in startup firms than well-established ones, see Lowell W. Busenitz \& Jay B. Barney, Differences Between Entrepreneurs and Managers in Large Organizations: Biases and Heuristics in Strategic Decision-Making, 12 J. BUS. VENTURING 9 (1997).

${ }^{190}$ See generally Kreps, supra note 109, at 106-08 (suggesting the influence of corporate reputation on perceptions about future behavior).

191 See text accompanying note 49 .

192 In other words, an optimistic culture or subculture may be an agency-cost reduction mechanism, thereby justifying substantial managerial attention to nurturing the most desirable set of beliefs. In some ways, we can generalize this point by saying that cultures mediate the egocentric perceptions of most human beings. In strong cultures, selfishness and self-serving inferences are dampened. But cultures cannot be manufactured at will; it takes persuasion to influence the collective perceptions of the group members. Hope and optimism, in turn, are particularly persuasive images when they can be communicated plausibly. Cf. Langevoort, supra note 3, at 633-34 (describing the motivations of investors to trust in optimistic advice).

${ }^{199}$ On the importance of trust, especially in periods of organizational stress, see Aneil K Mishra, Organizational Response to Crisis: The Centrality of Trust, in TRUST IN ORGANizATIONS, supra note 72, at 261. See also Deborah A. DeMott, Trust and Tension Within Corporations, 81 CORNELl L. REv. 1308, 1309-10 (1996) (discussing the role of 
behavior must be balanced against the rewards for cooperation. The greater the sense of future well-being from joint effort, the less likely opportunism becomes. Observable (and hence cascading) patterns of cooperation can then emerge-including reduced distortion in lines of information flow ${ }^{194}$-facilitating the development of a culture that has a higher-than-normal level of trust.

In light of the potentially adaptive virtue of optimism and related biases (for instance, the illusion of control), we can see how social forces that lead groups of managers not to see some risks (or to construe them unrealistically) could have a positive payoff on average. While there are serious costs associated with ignoring danger signs in a small subset of cases, these costs may be outweighed by the profitability produced by the benign influences of organizational selfdeception in others. When we couple this with the other virtue of risk deflection, the ability to maintain consistency and focus, we can see at least a plausible response to the "survival of the rational" claims of conventional economics. Indeed, although little of it relates specifically to organizational behavior, much of the work on the persistence of unrealistic optimism has been generated by sociobiologists working from strong Darwinian assumptions. ${ }^{195}$

trust when parties enter a relationship in pursuit of personal economic advantage); William G. Ouchi, Markets, Bureaucracies and Clans, 25 ADMIN. SCI. Q. 129, 130 (1980) (discussing the impact of trust on transaction costs). On the psychological mechanisms in group trust, see Debra Meyerson et al., Swift Trust and Temporary Groups, in TRUST IN ORGANIZATIONS, supra note 72, at 166. An implicit understanding along these lines thus facilitates thousands of daily interactions. See supra note 105. An interesting body of scholarship, in both law and economics, has considered the effects of breaches of implicit contract (a trust concept) on efficiency and morale. See, e.g., Bruce Chapman, Trust, Economic Rationality and the Corporate Fiduciary Obligation, $43 \mathrm{U}$. TORONTO L.J. 547 (1993) (challenging the contractual view of the corporation because of its failure to account for the duties of loyalty and trust). It would not be surprising to find that cultures that were highly optimistic generated the highest level of hope and thus the most intense feeling of betrayal when the optimistic bubble was popped. See Chip Heath et al., The Strategic Management of the Entitlement Process in the Employment Relationship, 14 STRATEGIC MGMT. J. 75, 80-82 (1993) (discussing the psychological processes operating to effectuate this result, particularly the problem of self-serving inference).

${ }^{194}$ See Mishra, supra note 193, at 273-75 (discussing trust as a "prerequisite to undistorted communication"); see also Karlene H. Roberts \& Charles A. O'Reilly, III, Failures in Upward Communication in Organizations: Three Possible Culprits, 17 AGAD. MGMT. J. 205, 208-09 (1974) (discussing the importance of trust as a facilitation of information exchange).

195 See generally LIONEL TIGER, OPTIMISM (1979) (discussing the phenomenon of personal optimism); supra note 188. While on the subject of evolution, we should sound a note of caution. For a variety of reasons, our economy is evolving away from an emphasis on firms that make a long-term commitment to a particular technology in 


\section{The Legal Implications of Bias}

If corporations habitually tend toward cognitive conservatism, overcommitment, overoptimism, and selfish inference, there is a considerable likelihood that the subjective forward-looking elements of their disclosure and publicity will have the potential to mislead. Of course, market professionals and other savvy investors will discount many kinds of corporate hype and, at least in those settings where efficiency properties predominate, such disclosures may have minimal market-price impact. ${ }^{196}$ On the assumption, however, that managers do have unique access to certain kinds of risk-related information such that some marketplace dependency on managerial inference is inevitable, ${ }^{197}$ the possibility of socially inefficient market-price distor-

favor of more flexible mechanisms for producing goods and delivering services. See Gilson, supra note 22, at 340-41 (describing the nexus between corporate governance mechanisms and diminishing product life span). Perhaps that shift will create a setting in which narrow vision and focus, and other myopic kinds of organizational biases we have identified, will have less capacity to survive than they have had previously. Surely, we must concede that the survivability of these biases is historically contingent, and research that looks at the current or past environment may not describe the future. For commentary on the balance between stability and adaptability, see Lance B. Kurke, Does Adaptation Preclude Adaptability?: Strategy and Performance, in INSTTTUTIONAL PATTERNS AND ORGANizATIONS 199 (Lynne G. Zucker ed., 1988). Although these points are well taken, my intuition is that both optimism and self-serving inference are likely to remain pervasive even if the virtues of narrowed focus and conservatism erode. Cf. Meyerson et al., supra note 193, at 186 (determining that positive illusions contribute to the resilience of swift trust in a temporary group).

${ }^{196}$ See, e.g., COX ET AL., supra note 11, at 61 (noting that "information as to the cost and performance of [a] new computer series was already widely known in the industry, so that [a] misstatement did not affect the mix of information" (citing Beissinger v. Rockwood Computer Corp., 529 F. Supp. 770, 781-82 (E.D. Pa. 1981))); Roger J. Dennis, Mandatory Disclosure Theory and Management Projections: A Law and Economics Perspective, 46 MD. L. REv. 1197, 1206 (1987) (finding that investors did not respond positively to enhanced mandatory continuous disclosure due to the efficient-market model); Ronald J. Gilson \& Reinier H. Kraakman, The Mechanisms of Market Efficiency, 70 VA. L. REV. 549, 635-42 (1984) (questioning the effect on prices based on mandatory disclosure requirements). Investment analysts and other professional investors can, in many cases, test management's inferences by contacting customers, suppliers, and other experts for alternative points of view about the company's prospects. To date, neither legal scholars nor economists have specified the point at which professional-investor reliance on managerial inference is apt to occur. There is a sense that even professionals may be subject to some predictable biases, notwithstanding market constraints. See, e.g., Tilman Ehrbeck \& Robert Waldmann, Why Are Professional Forecasters Biased?: Agency Versus Behavioral Explanations, 111 Q.J. ECON. 21 (1996) (discussing how to test for the biases of forecasters); see also Langevoort, supra note 12, at 869 (finding that "investment analysts and economic forecasters [may] overreact to certain information").

${ }^{197}$ Along these lines, one of the few areas where there is mandatory disclosure of some kind of future-oriented information is in the Management Discussion \& Analysis 
tion remains. The normative question then looms: What changes to the prevailing rules of securities regulation might we consider in light of this heretofore unexplored possibility?

The most natural response is consistent with the points made earlier about the relevance of information-flow blockages. ${ }^{198}$ If we are seriously interested in deterring corporate deception, then fraud liability should not turn on conscious awareness by the specific senior executives responsible for corporate communications of the misleading nature of their misstatements or omissions. I have doubts about how often, in hindsight, judges and juries would actually recognize an instance of cognitive blindness and refuse to impose liability. ${ }^{199}$ At least in principle, however, an awareness requirement much too readily protects the kinds of marketplace distortions that securities regulation wants to prevent.

To overcome this, the law would want to create incentives (if not direct requirements) to force the "debiasing" of corporate inference. Within the scienter-based regime of Rule 10b-5, the first step toward achieving this end would be to develop a definition of corporate scienter that focuses on the attribution of knowledge to the firm. Such emphasis would echo a comparable doctrinal development in the law of insider trading, within which liability turns on simple possession of information rather than identifying a specific misuse of it by natural persons within the organization. ${ }^{200}$ In response, corporations wishing to avoid liability would have an incentive to bring into the disclosure

portion of required SEC filings. The optimistic bias of these disclosures has been observed. See Moses L. Pava \& Marc J. Epstein, How Good Is MDEA as an Investment Tool?, $175 \mathrm{~J}$. ACCT. 51, 52-53 (1993) (noting that the SEC's original goals in requiring this section may not be satisfied in practice). Yet it still has the capacity to reveal new information and thus affect prices. See Stephen H. Bryan, Incremental Information Content of Required Disclosures Contained in Management Discussion and Analysis, 72 ACCT. REV. 285, 298 (1997) (discussing the short-term price impact of the SEC's mandatory disclosure requirement). Presumably, analysts apply some sort of bias discount that varies depending on issuers' reputation for credibility.

${ }^{198}$ See supra notes 8496.

199 For reasons having to do with the hindsight bias as well as the tendency to attribute blame to dispositional rather than situational factors, juries may not be moved by claims of lack of awareness based on cognitive bias. See Langevoort, supra note 6 (manuscript at 34-35) (suggesting that juries are motivated to explain bad events in terms of malfeasance). If this is the case, we might have too much enforcement, at least within the traditional understanding of the scienter requirement.

${ }^{200}$ See United States v. Teicher, 987 F.2d 112, 120-21 (2d Cir. 1993) (suggesting that insider-trading liability does not depend upon a showing that the information led to the trading and that "knowing possession" is enough); LANGEVOORT, supra note 34, $\S 3.04$ (discussing the inconsistent case law in this area). 
process persons not subject (or less subject) to the same biases. Depending on the type of information in question, management consultants, accounting firms, and law firms could offer a useful, though by no means fail-safe, therapeutic intervention. ${ }^{201}$

In areas of special concern, the law could go one step further and mandate such intervention. In essence, the due-diligence requirement for underwriters and accountants under section 11 of the Securities Act of $1933^{202}$ is based on a mistrust of management as the exclusive source of firm-specific information, ${ }^{203}$ thereby requiring a "bonding" of disclosure completeness and accuracy by outside professionals (who in turn also have their own reputational interests at stake). While this historic mistrust is probably based more on the fear of deliberate cheating than cognitive bias, the independent evaluation of data involved in a due-diligence investigation provides a useful antidote to bias in initial public offerings and other settings where it is both required and practicable. ${ }^{204}$

Securities regulation could also choose to extend this more broadly to some standard requiring ongoing disclosures by public companies. Requiring auditor certification of some kinds of projec-

${ }^{201}$ See generally Langevoort, supra note 6 (focusing primarily on the involvement of lawyers in the disclosure process). Some doubts about the accountant's motivation to detect fraud are expressed in Max H. Bazerman et al., The Impossibility of Auditor Independence, SLOAN MGMT. REV., Summer 1997, at 89. See also PFEFFER, supra note 126, at 249-54 (discussing consultants' biases in the process).

202 15 U.S.C. $\$ 77 \mathrm{k}(\mathrm{b})(3)$ (1994).

${ }^{203}$ See, e.g., Michael P. Dooley, The Effects of Civil Liability on Investment Banking and the New Issues Market, 58 VA. L. REV. 776, 802-10 (1972) (discussing the philosophy of section 11 liability); Merritt B. Fox, Shelf Registration, Integrated Disclosure and Underwriter Due Diligence: An Economic Analysis, 70 VA. L. REV. 1005, 1032 (1984) (concluding that underwriter due diligence improves the quality of market information); see also Reinier H. Kraakman, Corporate Liability Strategies and the Costs of Legal Controls, 93 YALE L.J. 857, 897 (1984) (discussing the impact of such gatekeeper liability).

${ }^{204}$ Indeed, it might be possible to tell the story of the most famous of all duediligence cases, Escott v. BarChris Construction Corp., 283 F. Supp. 643, 688 (S.D.N.Y. 1968) (holding that the defendants failed to meet the burden of proof that damages suffered by the plaintiffs were caused by factors other than material misrepresentations and omissions in the prospectus), as one in which (in contrast to the court's interpretation) management optimistically underestimated the severity of the risk associated with building bowling alleys for customers. Had they done their jobs, the various professionals might have introduced a less rosy assessment of that risk. To simplify, the essence of the fraud allegations in BarChris was the nondisclosure of contractual provisions relating to the company's construction projects, pushing much of the risk of marketplace failure on the company. See id. at 653-54. Without questioning the court's conclusion relating to the materiality of this information, it is not implausible that senior management failed to appreciate the nature and extent of the risk it was retaining because of some biased perception. 
tions and estimates would create this sort of third-party intervention in an area highly susceptible to bias. Even more aggressive would be a required due-diligence investigation of publicly traded firms every three or five years. ${ }^{205}$ Conversely, the SEC might take a stronger stand against the loss of due diligence that has come from the gradual shift of more and more capital raising to the shelf-registration system. That system preserves due-diligence liability but makes it practically impossible to do it well once the registrant has decided that the market window of opportunity is open, but may close in a day or two. ${ }^{206}$

There is no lack of possible interventions, but two concerns should also be evident. First, note the difficulty in achieving the gains. With respect to highly subjective kinds of construal-for instance, those regarding research and development, product quality, or marketing- "audit" or due-diligence techniques may not work particularly well. Information of that sort cannot easily be separated from the perceptions of those with firsthand knowledge of the business. The natural response of managers and other employees faced with attempts by skeptical third parties to assess their objectivity may well be either to freeze the third parties out of the information loop or engage in impression-management techniques that blur the prevailing reality. ${ }^{207}$

Second, note the magnitude of the precaution costs involved. As discussed earlier, investors pay heavily for third-party investigations, both in the direct fees paid by the issuer to the professionals for their time and effort, and in the risk premium to compensate for their liability exposure. ${ }^{208}$ Whether this delivers fair value, given savvy investors' ability to filter out some biases and plumb alternative sources of

${ }^{205}$ See James D. Cox, The Fundamentals of an Electronic-Based Federal Securities Act, 75 WASH. U. L.Q. 857, 883 (1997) (proposing a continuous reporting system, perhaps every third year).

${ }^{206}$ See Committee on Fed. Regulation of Sec., Report of the Task Force on Sellers' Due Diligence and Similar Defenses Under the Federal Securities Laws, 48 Bus. LAw. 1185, 1207 (1993) (noting the inadequate time available for underwriters to discharge their duediligence responsibilities adequately).

${ }^{207}$ In addition, it is possible that cognitive biases may affect the ability of such outsiders to perceive the risk, especially if they are not really outsiders but have some continuing relationship (and commitment) to the company. With respect to auditors, see Bazerman et al., supra note 201, suggesting that it is "psychologically impossible for auditors to maintain their objectivity," id. at 90; and Mark W. Nelson \& William R. Kenney, The Effect of Ambiguity on Loss Contingency Reporting Judgments, 72 ACCT. REV. 257 (1997), concluding that "users may expect a more conservative reaction to ambiguity than auditors provide," id. at 259.

${ }^{203}$ See supra text accompanying notes 92-94. 
information anyway, is open to question. ${ }^{209}$ We might also worry about whether shifting to a possession-based corporate-scienter regime, or one of enhanced due-diligence responsibilities, would make it too easy for plaintiffs to bring suits of questionable merit, which nonetheless force settlement, causing an unnecessary shifting of money from shareholders of the issuer to a small class of purchasers or sellers, and their attorneys. ${ }^{210}$

These are fairly direct costs. But one is also entitled to ask whether biases built on overoptimism, at least, are ones with which we really want to interfere through legal intervention, even if we could. If optimism is adaptive in that companies do better if they develop belief systems that deflect awareness of the seriousness of some kinds of risks, is it really the kind of belief system we want to discourage? Social psychologists suggest that the class of persons least prone to excessive optimism and the illusion of control is the clinically depressed. ${ }^{211}$ We run the risk of having third-party interventions causing official company statements that, if successful, dampen the internal morale of the senior managers and perhaps the company culture as a whole. Those that fall short of success simply operate as expensive and disruptive monitoring systems with little to show in the way of improved disclosure. ${ }^{212}$

Those uncomfortable with these various costs might be tempted to move to the opposite extreme and seek to immunize overoptimism from legal attack. Indeed, there has been a fascinating line of cases

${ }^{209}$ See Stephen J. Choi, Company Registration: Toward a Status Based Antifraud Regime, 64 U. CHI. L. REV. 567, 587 (1997) (discussing the ability of third parties to perform gatekeeper functions).

${ }^{210}$ Under the pleading standards put in place in 1995, plaintiffs face dismissal of their suits if they cannot put forward facts giving rise to a strong inference of scienter. See 15 U.S.C. $\$ 78 \mathrm{u}-4$ (b) (2) (Supp. 1995). In many ways, this is the most significant hurdle imposed by the legislation. See Elliott J. Weiss, The New Securities Fraud Pleading Requirements: Speed Bump or Road Block?, 38 ARIZ. L. REV. 675, 676 (1996) (concluding that the pleading requirement is "more of a speed bump than a road block" for a plaintiff because of the different factual requirements of different courts). It does seem likely that plaintiffs are more likely to survive the motion to dismiss (and thereby gain immense settlement leverage) if they are simply required to create an inference that the truth was within the organization at large, rather than having to create the inference that the corporate speaker knew the truth.

${ }^{211}$ See FISKE \& TAYLOR, supra note 115, at 214 (suggesting that individuals with measured low selfesteem or moderate depression, or both, exhibit more accurate selfappraisals).

${ }^{212}$ My sense is that in many situations the lawyer's challenge is a severe one: $\mathrm{Bi}-$ ased cultures may strongly resist meaningful public acknowledgment of the seriousness of risk, leading to boilerplate risk disclosure at best. 
in the 1990s, beginning with the Fourth Circuit's decision in Raab $v$. General Physics Corp., ${ }^{213}$ that goes substantially in this direction. Under this view, general corporate statements of optimism are immaterial as a matter of law. While at base this is just common sense-some statements of optimism are so general and contentless (for example, "This is a great company with a great future.") that we can hardly imagine any investor seriously relying on it alone, or even a cluster of similar platitudes-the cases themselves protect statements that are far from standard puffery. Concern that this provides too much room to deceive the reasonable investor has led other courts, like the First Circuit in Shaw v. Digital Equipment Corp. ${ }^{214}$ to limit the doctrine. In terms of protecting reasonable reliance, the parsimonious use of this doctrine is clearly correct. When viewed in context, general statements of optimism can mislead. ${ }^{215}$ On the other hand, Raab and its progeny do create the ability to weed out-without the need for factintensive discovery into corporate state of mind-the kinds of cases where optimistic bias, rather than intentional deceit, is particularly likely to have driven the allegedly misleading disclosure. ${ }^{216}$

${ }^{215} 4$ F.3d 286, 291 (4th Cir. 1993) (holding that predictions about future earnings in annual report are immaterial); see also Eisenstadt v. Centel Corp., 113 F.3d 738, 746 (7th Cir. 1997) (holding that "investors would have expected no less" than optimistic statements); Hillson Partners Ltd. Partnership v. Adage, Inc., 42 F.3d 204, 216-19 (4th Cir. 1994) (holding that projected sales statements are not actionable); Malone v. Microdyne Corp., 26 F.3d 471, 479-80 (4th Cir. 1994) (holding that a statement expressing "comfort" with an analyst's prediction of a company's future earnings was not actionable); In re Gupta Sec. Litig., 900 F. Supp. 1217, 123435 (N.D. Cal. 1994) (holding that the projected earnings had sufficient cautionary language to be nonactionable). In addition, one could justify such a rule by reference to the possibility that an overly optimistic corporate face is so natural and normal that the sophisticated market simply assumes the presence of the bias. See supra text accompanying notes 49-51.

${ }^{214} 82$ F.3d 1194, 1213-14 (1st Gir. 1996) (overruling the district court and allowing plaintiff's allegations of materially misleading "soft" statements in a prospectus to stand).

${ }^{215}$ Take, for example, a situation where independent analysts predicted a good future, and management had a prior reputation for credibility. Here a positive general statement might have a lulling effect, even on professional investors.

${ }^{216}$ While the Raab line of cases only protects general statements of optimism, there are other possibilities open to one inclined to protect optimism. The new safe harbor for forward-looking information protects projections and estimates by seasoned companies if made either without actual knowledge of their falsity or with "meaningful cautionary statements" accompanying them. 15 U.S.C. $\$ \S 77 z-2(c)(1)(A), 78 u-$ 5(c)(1)(A) (Supp. 1995); see Carl W. Schneider \& Jay A. Dubow, Forward-Looking Information-Navigating in the Safe Harbor, 5I BuS. LAw. 1071, 1073 (1996) (discussing the safe-harbor provisions for forward-looking statements after the Private Securities Litigation Reform Act of 1995). This readily provides protection to optimistic disclosure that complies with the fairly minimal protective standards. More broadly, one could 
The tensions for securities-law doctrine raised by the possibility of bias are present with respect to all forms of publicity, but most importantly with respect to concealment cases. Under the so-called "duty to update" adopted by some circuits, for example, companies have a proactive responsibility to inform the marketplace when events evolve in such a way as to render misleading some prior statement upon which the market is still relying. In re Time Warmer Inc. Securities Litigation is a good example, where the Second Circuit found that Time Warner might have violated Rule $10 \mathrm{~b}-5$ by not issuing a press release after it became clear that its prior strategy of seeking financial partners would have to be abandoned in favor of a dilutive stock offering. ${ }^{217}$ Courts have not done a good job of explaining the scienter requirement here: Must there be some conscious awareness, or some realization, that continued silence is (or in terms of recklessness, may be) misleading? ? $^{218}$ Or is that a legal question of duty, for which ignorance is no excuse-in which case scienter is largely meaningless? Assuming the former, one can readily see how difficult it will be for management to come to a conscious awareness of the need to acknowledge the change, given management's commitment to the prior course of action and its natural optimism that success may still be just around the corner. The risk of hindsight bias here is also extremely high, creating another reason for those who worry about the spillover costs of regulation to doubt that a broad duty to update (or at least heavy civil liability for breach) is really a sensible legal doctrine. ${ }^{219}$

reconceptualize the focus of securities-law disclosure away from investment-related information generally (which is naturally susceptible to bias) in favor of a system that simply tries to force disclosure of matters relating to managerial competence and integrity. See Paul G. Mahoney, Mandatory Disclosure as a Solution to Agency Problems, 62 U. CHI. L. REv. 1047, 1090-93 (1995) (discussing the efficiency gains of agency information).

${ }^{217} 9$ F.3d 259, 267-68 (2d Cir. 1993); see also Greenfield v. Heublein, Inc., 742 F.2d 751, 758-60 (3d Cir. 1984) (recognizing the theory, but holding that no duty to correct existed because defendant was never under a duty to disclose its first statement). The duty exists when management has made a specific forward-looking statement that is still "alive" in the marketplace at the time the new information appears. See Ross v. A.H. Robins Co., 465 F. Supp. 904, 908 (S.D.N.Y. 1979) ("It is now clear that there is a duty to correct or revise a prior statement ... so long as the prior statement[] remains 'alive."'), rev'd on other grounds, 697 F.2d 545 (2d Cir. 1979); COX ET AL., supra note 11, at 713-14 (discussing duty to update).

${ }^{218}$ On this topic, but without clear resolution, see State Teachers Retirement Board $v$. Fluor Corp., 654 F.2d 843, 850-51 (2d Cir. 1981) (holding that the defendant had no obligation to disclose contract and that the defendant did not act recklessly or with fraudulent intent by failing to disclose).

${ }^{219}$ Not all courts have been impressed with the doctrine. See Stransky v. Cummins Engine Co., 51 F.3d 1329, 1332 (7th Cir. 1995) (rejecting the doctrine); Backman v. 


\section{BEYOND CORPORATE DISClOSURE: OTHER SOCIAL HARMS}

From the foregoing prediction that a corporation's disclosure to investors may sometimes be distorted, not in bad faith, but rather because cognitive forces and information-flow problems lead to a skewed perception of reality by senior officials, we can extend the same story to other sorts of social harms with little difficulty. At the risk of some repetition, the following account is a generic story of "wrongdoing" that is more a failure of rationality than an example of venality. My aim here is simply to suggest that this genre of organization theory has the potential to inform a broad range of issues in civil and criminal law, where the anthropomorphic conception of the firm still weighs heavily as well. ${ }^{220}$

Responding to strong internal and external pressures both to grow and to increase profitability, most management groups search continually for new technologies to exploit, such as a new product line or new mechanisms for producing current ones more efficiently. An auto manufacturer, for example, might determine that it is worthwhile to introduce a highly inexpensive automobile to play in the market for young or low-income purchasers (such as the Pinto, ${ }^{221}$ manufactured by Ford in the 1970s). Alternatively, a textile manufacturer might purchase more efficient, high-speed looms to respond more effectively to foreign competition. ${ }^{222}$ Predictably, some of those judgments will turn out to be socially harmful-for example, a deci-

Polaroid Corp., 910 F.2d 10, 16-18 (1st Cir. 1990) (en banc) (refusing to apply the doctrine to the facts of the case and raising questions about its viability). Indeed, the Second Circuit itself recognized that the duty must be limited lest it interfere with legitimate corporate confidentiality needs. See San Leandro Emergency Med. Group Profit Sharing Plan v. Philip Morris Cos., 75 F.3d 801, 809-10 (2d Cir. 1996) ("We are concerned about interpreting the securities laws to force companies to give their competitors advance notice of sensitive pricing information.").

${ }^{220}$ A recent symposium in the Southern California Law Review was devoted to organizational-tort liability, with special attention to issues of vicarious liability. See Corporate Tort Law Symposium, 69 S. CAL. L. REV. 1679 (1996). The "anthropomorphic" claim is made in Steven P. Croley, Vicarious Liability in Tort: On the Sources and Limits of Employee Reasonableness, 69 S. CAL. L. REV. 1705 (1996). On criminal law, see sources cited supra note 4, summarizing various uses of organization theory. See also Barry D. Baysinger, Organization Theory and the Criminal Liability of Organizations, 71 B.U. L. REV. 341, 361-63 (1991) (evaluating the United States Sentencing Commission's guidelines for organizational crimes from the perspective of organization theory). See generally Symposium, A National Conference on Sentencing of the Corporation, 71 B.U. L. REV. 189 (1991).

${ }^{221}$ The Pinto case, of course, is well studied as a matter both of law and business ethics. See, e.g., Gioia, supra note 118, at 380-81 (discussing Ford's introduction of the Pinto in record time to compete with foreign corporations).

${ }^{222}$ This example comes from JACKALI, supra note 69 , at 101-05. 
sion to lower the safety level of a car to passengers and other motorists, or increasing the noise level of looms, causing gradual hearing loss to workers. The normal, culturally conditioned response is to say that these corporations have chosen profits over social responsibility deliberately. Yet, in many cases, the ultimate costs (monetary and reputational) after being caught and penalized exceed the gains that reasonably could have been predicted at the time. ${ }^{223}$

Sometimes firms do simply discover some patentable new product or technology and enter the development and marketing stage completely confident of success. But this rarely occurs. Most strategic steps are taken in an atmosphere of extremely high ambiguity, especially in the early stages. A new product or manufacturing process is an interesting possibility, but answers to questions of successful manufacture, time frame, cost, market impact, and risk are all highly uncertain. The high-level executive decision to move ahead with such a project is a political act, for it will place resources and opportunities in the hands of some managers rather than others. The political battling for resources requires careful impression management (most effective, as we have seen, if the proponents believe their own selfserving representations). ${ }^{24}$ Here, natural optimism, coupled with impression-management demands, leads to presentations to top officials that put aside risks (which are highly indeterminate anyway at this early stage) and overstate the project's potential. ${ }^{225}$ The senior executives faced with the resource-allocation decision probably recognize the likely bias, and other managers competing for the same resources will try to pick at the idea's soft spots. "Go ahead" decisions are not easy to elicit. Even so, most senior executives also recognize that decisions must be made, even in the face of high ambiguity.

${ }^{223}$ That fact alone is not dispositive, of course. There can be rational choices for social harm, for instance, if either the risk of detection or amount of penalty is suboptimal. See generally GeORGE EADES \& PETER REUTER, DESIGNING SAFER PRODUCTS 52-72 (1983) (discussing some of the decisionmaking behind the manufacture of dangerous materials from a more rationalist, but still critical, perspective); Wendy $\mathrm{E}$. Wagner, Choosing Ignorance in the Manufacture of Toxic Products, 82 CORNELL L. REV. 773, 810-27 (1997) (arguing that the current system of liability encourages manufacturers to make socially nonoptimal decisions concerning product-safety research).

224 See supra notes 148-55 and accompanying text.

${ }^{225}$ For a case study on this problem, see Andrew D. Brown, Politics, Symbolic Action and Myth Making in Pursuit of Legitimacy, 15 ORG. STUD. 861 (1994). See also Andrew H. Van de Ven \& Douglas Polley, Leaming While Innovating, 3 ORG. SCI. 92, 106-07 (1992) (discussing the potential for interference with learning caused by these representations). 
Their social role prizes decisiveness and action, ${ }^{226}$ and they recognize that waiting for ambiguity to be resolved before committing to any significant course of action invites organizational paralysis. For these reasons, choices are made, typically with a commitment to monitor the chosen project in its early stages so that it can be abandoned at relatively low cost should difficulties or risks surface.

Once the project begins, those closest to the situation (the winners) have ample motivation to believe in its efficacy-their natural optimism has now been rewarded by positive feedback from the top. They are committed to a positive schema, and they recognize the political reality that the project can still be killed, so they wish to manage the flow of information to prevent this from happening. ${ }^{227}$ An environment is thus created that leads those with immediate access to information to sense, without full awareness necessarily, that riskrelated information will provoke stress and potential loss. Common defense mechanisms are employed. After all, it is still early in the project, so that any risks that surface at a conscious level remain speculative and temporally remote, and thus are still susceptible to rationalization. It becomes easy to explain them away and preserve the aura of optimism. As a result, either the risks are not reported at all, or they are communicated upward in a way that dulls them. Even if there should be some conscious shading of the truth in reports to superiors, it is probably not in bad faith, given the winners' optimistic schema. Omission of certain information can be readily justified as a means of avoiding disclosure that superiors might take out of context, overreact to, or otherwise misunderstand. Higher-ups are then unlikely to sense serious cause for concern.

To the extent that there is significant diffusion of responsibility for surveying incoming information for danger signs, the ability to deflect signs of risk increases. Diffusion increases the ambiguity associated with one's own stock of data, and the act of raising a red flag

${ }^{226}$ See NILS BRUNSSON, THE IRRATIONAL ORGANIZATION 21-28 (1985) (noting that the role of a decisionmaker is to motivate the organization to action and that uncertainty can lead to bewilderment and confusion); ROBERT G. LORD \& KAREN J. MAHER, LEADERSHIP AND INFORMATIONAL PROCESSES 66 (1991) (noting that one corporate leader's "personality, being much more conservative, indecisive, and aloof, did not fit well with expectations for typical leaders" (citation omitted)).

${ }^{227}$ This portion of the story borrows from Darley's account, see Darley, supra note 160 , at 21-22, 28-36, of corporate misbehavior, especially his recounting, from a socialpsychological perspective, of B.F. Goodrich's production of faulty brake assemblies for military aircraft, based on Kermit Vandivier, Why Should My Conscience Bother Me?, in CORPORATE VIOLENCE 145 (Stuart L. Hills ed., 1987). 
threatens the newly established (and probably quite strong) group cohesion. If the private information is ambiguous and no one else acts troubled, the pressure is strong to dismiss the information.

Now let us assume that more significant, and less ambiguous, danger signs gradually appear to those with the most direct access to the information. Here, of course, the biases are likely to shift even more from the cognitive to the motivated. Postdecisional commitment becomes stronger: The winners are not only emotionally, but also economically, invested in the project, the unwinding of which is likely to have very troublesome career implications for those who find themselves in this particular probationary crucible. They may well be in something of a personal "last period." Their psychological resistance hardens, and the temptation to distort disconfirming information increases-still, however, not necessarily in bad faith (though, at this point, some background awareness of trouble may surface). The competition between conscience and motivated rationalization continues until the information becomes so clear-cut that its implications are unavoidable. Once again, to the extent that access to information is highly diffused, that may take quite some time. Presumably there comes a time, however, at which an awareness of the project's risks or dangers crystallizes. At that point, an active cover-up might begin, though at the same time the once-thought-to-be winners may well also start believing in a self-serving fashion that sufficient disclosure of the risks was made such that responsibility for continuing the project rests more with those higher up than with them. The important point, of course, is that the final awareness of the risk or harm occurs somewhat after the point in time at which, both practically and legally, the responsible actors are likely to be held accountable. This is the optimism-commitment whipsaw effect. ${ }^{228}$ As one of the more polite sayings goes, the managers find themselves "knee-deep in the big muddy." 229

As to supervisory executives a step or two removed from the project itself, their ability to monitor is compromised by two basic factors. The first is the likely distortion of information. Even if some senior

${ }^{223}$ See David C. Wilson et al., How Organizations Can Overbalance: Decision Overreach as a Reason for Failure, 39 AM. BEHAV. SCI. 995, 1005-06 (1996) (discussing the problem of overfamiliarity as contributing to overreach).

${ }^{229}$ Barry M. Staw et al., Knee-Deep in the Big Muddy: A Study of Escalating Commitment to a Chosen Course of Action, 16 ORG. BEHAV. \& HUM. PERFORMANCE 27 (1976) (quoting the title); see id. at 28-30 (discussing investors' tendency to commit additional resources to a poor investment in order to justify the initial investment). 
managers have private suspicions about the possibility of bias from below, there are often no alternative sources of data in order to test for it. As Chris Argyris argues, many corporate cultures discourage open expressions of doubt and skepticism, which skew the information flow. ${ }^{230}$ The second is the increasing commitment of the superior who approved the project as the investment in the project increases.

Nearly all firms do have accountability or internal-control systems designed to prevent information distortion of a gross sort. Accounting-control systems are well-suited to monitor the use and disposition of corporate assets, but on a basis that emphasizes current and historic reporting, not future trends. Information relating to product and technology risks shows up only very late in budgetary or financial controls. There may be other compliance functions as well, but these all tend to lack direct access to information about subjective matters such as product development and engineering defects. What information senior managers do see is likely to be fairly ambiguous, and their own biases (cognitive conservatism if nothing else) can readily lead to their ignoring some kinds of risks. Dennis Gioia's study of the failure of Ford's recall departments to become aware of the Pinto's danger to consumers in light of its heavy workload (such that limited time and attention could be given to any particular matter), and the ease with which initial crash information could be explained away in terms that suggested minimal, containable danger, provides a good example of the limits of external monitoring. ${ }^{231}$

Now that we have a plausible account that can fit many sorts of "corporate misconduct" cases, from the manufacture of defective products to the disposal of toxic waste to the adoption of manufacturing processes that threaten worker health or safety-all potential torts or crimes-we might ask of what significance it all is. Because both tort and criminal law pursue so many competing objectives, I could not hope to offer a single answer. ${ }^{232}$ The attribution of blame is a so-

${ }^{230}$ See supra note 78.

${ }^{231}$ See Gioia, supra note 118 , at $386-88$. Of course, companies could build more intrusive and effective monitoring systems, but these are likely to be very expensive and imperfect, threatening to overall corporate morale (and hence efficiency), and subject to manipulation in any event. See supra note 72 and accompanying text.

${ }^{232}$ There are obvious questions about whether it is "unreasonable" to ignore risks because of very natural and commonplace psychological and social mechanisms. Cognitive limitations have become increasingly interesting to torts scholars, in terms of both victim and wrongdoer behavior. See, e.g., Howard A. Latin, Problem-Solving Behavior and Theories of Tort Liability, 73 CAL. L. REV. 677, 745 (1985) (arguing that tort liability and compensation systems should be keyed to the attention parties give to 
cial act for which blameworthiness must sometimes be manufactured to maintain the illusion of a controllable world, especially when there are identifiable victims. ${ }^{233}$

But some observations may be useful, if not dispositive. For instance, from an economic standpoint, we see from the above how difficult it might be for companies to price rationally to cover the risk of future harms from new products. In terms of deterrence, to say that organizations have natural biases hardly argues by itself for a shift from vicarious to individual actor-based liability; individuals are biased as well, maybe more so. ${ }^{234}$ While groups sometimes exacerbate biases, that is not always the case, and there is always the potential to build into the corporate system checks and balances that reduce the likelihood that one or a small number of biased managers will cause significant social harm.

What does seem likely is that highly indeterminate legal standards-such as those based on "reasonableness" or "good faith"-will have a less direct impact on firm behavior than we would like to think. ${ }^{295}$ The managerial bias is to perceive the firm's actions as both reasonable and in good faith. In this light, a legal rule mandating that a company face a penalty if it acts unreasonably will not be all that potent in affecting day-to-day activity. A rule mandating "reasonableness" or "good faith" ignores the many reasons that managers, and thus organizations, resist becoming aware of either unreasonableness or bad faith. Because managers fail to perceive unreasonableness and bad faith, they cannot modify their conduct in response to the legal rule. ${ }^{236}$

risk); W. Kip Viscusi, Individual Rationality, Hazard Warnings and the Foundations of Tort Law, 48 RUTGERS L. REV. 625, 628 (1996) (assessing the degree to which people can process hazard warnings and how cognitive limitations affect the criteria for hazardwarning policy). For comparable implications for tax law at the individual level, see Jeff T. Casey \& John T. Scholz, Beyond Deterrence: Behavioral Decision Theory and Tax Compliance, 25 L. \& SOC'Y REV. 821 (1991).

${ }^{293}$ See, e.g., MARY DOUGLAS, RISK AND BLAME 6 (1992) (suggesting that blame coerces standardized behavior within a community).

${ }^{234}$ See Croley, supra note 220, at 1719-25 (discussing biases of the individual).

${ }^{255}$ On the relationship between legal ambiguity and organizational response, see Suchman \& Edelman, supra note 6, at 932-33.

${ }^{225}$ While insensitivity is the problem on which we are focusing, sensitivity may also become an issue. Scholars are increasingly willing to recognize "overlegalized" organizational responses. These are most likely to occur either when the legal dictate is highly salient and unambiguous, or when peer organizations have responded visibly so that a claim to legitimacy is at stake. See Donna M. Randall \& Douglas D. Baker, The Threat of Legal Liability and Managerial Decision Making: Regulation of Reproductive Health in the Workplace, in THE LEGALISTIC ORGANIZATION, supra note 75, at 169, 181 
There are thus grounds to fear organizational insensitivity to certain kinds of legal dictates. ${ }^{237}$ The natural response for the law would be to increase the sanctions, hoping to make the law salient enough to break through the organization's thick cognitive defenses. ${ }^{238}$ As

(discussing a large mining firm which adopted extensive fetal-protection policies as a result of "vivid cues of legal liability"). Additionally, when there are competing claims within the organization about the proper course of action, legal dictates (both to avoid the threat of liability and to gain external legitimacy) can be used to break the logjam. See Martha S. Feldman \& Alan J. Levy, Effects of Legal Context on Decisionmaking Under Ambiguity, in THE LEGALISTIC ORGANIZATION, supra note 75, at 109, 127-28 ("[T] he law narrows the frame of reference and limits what is relevant to decision making in at least three specific ways. It limits the issues that are under consideration. It specifies procedures for introducing information as relevant to an issue. It establishes definitions that constrain all claimants."). It is entirely possible that legal actors within organizations may overstate the law's dictates (or overstate its ambiguity) to give themselves a greater claim to organizational resources. See Lauren B. Edelman et al., Professional Construction of Law: The Inflated Threat of Wrongful Discharge, 26 L. \& Soc'Y REv. 47, 80 (1992) (discussing overstatement of wrongful-discharge law by the legal and personnel professions); Donald C. Langevoort \& Robert $\mathrm{K}$ Rasmussen, Skewing the Results: The Role of Lawyers in Transmitting Legal Rules, 5S. CAL. INTERDISC. L.J. 375, 434 (1997) ("[L]awyers whose writing or speaking deals with the management of risk are motivated to inflate the seriousness of those risks in order to justify the claim that substantial skill and expertise is required to deflect them.").

${ }^{237}$ For an exploration of sensitivity to legal dictates generally in tort law, see Gary T. Schwartz, Reality in the Economic Analysis of Tont Law: Does Tort Law Really Deter?, 42 UCLA L. REV. 377 (1994). See also Wagner, supra note 223, at 810-22 (arguing that current tort law discourages safety research). To be sure, as noted above, high sanctions can prompt certain kinds of ex ante structural responses to minimize the likelihood of unlawful behavior. But we also have seen that monitoring and detection systems work better for some kinds of harms than others. A strong threat of liability for hazardouswaste discharge, for instance, can prompt firms to establish environmental audit and testing offices outside of the normal lines of operational authority to avoid the problem caused by biased perception and reporting of environmental compliance by plant managers. See Max H. Bazerman et al., Environmental Degradation: Exploring the Rift Between Environmentally Benign Attitudes and Environmentally Destructive Behaviors, in CODES OF CONDUCT, supra note 149, at 256, 261-66 (discussing self-serving biases that impede people's ability to address environmental problems). In fact, there is no phase of a corporation's business that could not be double-checked by some independent authority from within or outside the firm that is specifically charged with establishing legal compliance. Independent monitors would lack the kinds of biases borne of commitment and conflict of interest that plague the primary line managers. Yet we rarely observe such intrusive compliance mechanisms. The reason, probably, is that the risk of serious defective products or harmful manufacturing processes is low anyway, so that highly expensive monitoring and testing systems are hard to justify. Their indirect costs, as we noted earlier, are also considerable, since overprecaution puts the firm at a severe competitive disadvantage. See supra notes 208-10 and accompanying text. Furthermore, senior managers are likely to underestimate the possibility of the harm occurring in the first place, and may well overestimate their ability to detect and control it on a day-to-day basis through more normal oversight of their line managers.

${ }^{238}$ Obviously, this is not the only strategy. Government monitoring or required third-party intervention could also address the problem, but again, at considerable 
sanctions grow more draconian, however, we encounter the familiar problem of overprecaution. ${ }^{239}$ Firms will add layers of legal audit, product testing, and other compliance units, which impose a burden on productivity, slowing down research and development timetables, and making it more likely that the company will forgo attractive competitive opportunities. The risks associated with the overlegalized corporation are well noted in the literature, ${ }^{240}$ and without a more sophisticated empirical understanding of organizational behavior, it is hard to predict whether any given high sanction will tend to overdeter rather than strike the right balance.

\section{CONCLUSION}

Because organizations are so pervasive in society, theories of organizational behavior are rarely far from the surface in legal discourse. When tort law asks about deterring the manufacture of dangerous products, or securities law about the desire to compel truthful disclosure to investors, the problem is posed clearly: Whatever rule or policy the law favors will have to affect the behavior of a disparate but interrelated group of human actors, not just a single individual, if it is to be effective. Addressing this intelligently demands that we know something about how behavior changes and outcomes occur in settings of diffused, but connected, power and responsibility.

Precisely because so many important normative matters in law depend on implicit (often naive) theories of organizational behavior, building a more robust account of such behavior is intellectually valuable. In practical terms, moreover, there is virtue in drawing normative conclusions from accounts that conform better to the often jaundiced intuitions and experience of judges, administrators, and other

cost. Although it is beyond the scope of this Article, there is ample reason to believe that government agents bring their own biases to bear on regulatory problems, creating different-but still costly-distortions. See, e.g., Clayton P. Gillette \& James E. Krier, Risk, Courts, and Agencies, 138 U. PA. L. REV. 1027, 1090-99 (1990) (discussing decisionmaking biases of agencies).

${ }^{239}$ See Bruce Chapman, Corporate Tort Liability and the Problem of Overcompliance, $69 \mathrm{~S}$. CAL. L. REV. 1679, 1687-94 (1996) (discussing the problem of excessive levels of corporate care). Chapman's fear that corporate overcompliance may be more of a problem than undercompliance may be correct for any number of reasons outside the scope of this Article. My point is simply that tort law should take into account the potential for cognitive resistance in assessing its general strategy.

${ }^{210}$ See, e.g., Jeffrey Pfeffer, The Costs of Legalization: The Hidden Dangers of Increasingly Formalized Control, in THE LEGALISTIC ORGANIZATION, supra note 75, at 329 (discussing the costs of the "legalistic mentality" in American corporations). 
policymakers on the subject of organizational rationality. While I hope to have generated a handful of usable practical insights for the formulation of securities-law policy, this Article is also meant to be an early step toward the development of a usable general theory on how organizations respond to legal dictates. Assuming that these insights survive criticism and testing, the kinds of hypotheses drawn here regarding organizational cognition and rationality could eventually help both scholars and policymakers assess with far greater realism and sensitivity the costs and benefits of alternative legal strategies in those settings in which organizations are dominant economic actors. For either securities law or the law generally, that would be no small contribution. 